\title{
Sobre "La cadena de custodia de la prueba en el proceso penal", de Geraldo Prado
}

\author{
About "The chain of custody of evidence in \\ criminal proceedings", by Geraldo Prado*
}

Antonio Vieira ${ }^{* *}$

Saulo Murilo de Oliveira Mattos ${ }^{* * *}$

Recepción: 02/11/2020

Evaluación: 11/11/2020

Aceptación final: 13/11/2020

\begin{abstract}
Resumen: El presente artículo analiza la obra La cadena de custodia de la prueba en el proceso penal, destacando las construcciones teóricas e interdisciplinarias (filosofía, política y epistemología) desarrolladas por Geraldo Prado sobre este instituto procesal, que, tras la publicación del mencionado libro, se incorporó al Código Procesal Penal brasilero por Ley $\mathrm{n}^{\circ} 13.964 / 2019$. Se explican los conceptos de verdad como indicador
\end{abstract}

* Traducción del portugés de Valentina Risso. [N. de T.: Los autores analizan el libro de Prado A cadeia de custódia da prova no processo penal, en su versión en portugués, por lo tanto las citas bibliográficas se vinculan con dicha obra. No obstante, para facilitar a los lectores la reseña realizada he colocado su título en español, tal como se ha publicado por Ed. Marcial Pons, 2019, traducción de Laura Criado Sánchez.]

** Profesor de Derecho Procesal Penal de la Universidade Católica do Salvador, Brasil, maestría en Razonamiento Probatorio por la Universidad de Girona/Es, miembro fundador y ex-presidente del Instituto Baiano de Direito Processual Penal (IBADPP). Correo electrónico: antonio@vieiraadv.com.br

${ }^{* * *}$ Fiscal del Ministerio Público de Bahía, maestría de la Universidade Federal da Bahia, Brasil, maestrando en Razonamiento Probatorio de la Universidad de Girona /Es, profesor de proceso penal invitado del posgrado en Ciencias Criminales de la Universidade Católica do Salvador. Asociado del Instituto Baiano de Direito Processual Penal (IBADPP). Correo electrónico: mattossaulo@gmail.com

Los autores agradecen a Caio Badaró Massena, por leer el texto con atención y enviar comentarios y sugerencias. 
epistémico y proceso como dispositivo, recurriendo a las fuentes de lectura (Michel Foucault, Giorgio Agamben, Luigi Ferrajoli, Rui Cunha Martins, entre otros) utilizadas por Geraldo Prado. Se muestra como la propuesta teórico-práctica de este autor, además de identificar la necesidad de una seria reflexión epistemológica sobra la preservación de la integridad de las fuentes de prueba, retoma, ampliamente, las discusiones sobre la relación entre fiabilidad probatoria, la etapa intermedia del proceso penal (admisibilidad de la acusación) y la valoración judicial del contexto probatorio. Palabras claves: Epistemología, proceso penal como dispositivo, cadena de custodia y fiabilidad probatoria.

\begin{abstract}
This essay analyzes the book A cadeia de custódia da prova no processo penal, highlighting the theoretical and interdisciplinary constructions (philosophy, politics and epistemology) developed by Geraldo Prado about this procedural institute, which, after the book was published, was inserted into the Brazilian Criminal Procedure Code by Law 13.964/2019. The article intends to explain the concepts of truth as an epistemic indicator and the idea of criminal procedure as a device, using Prado's theoretical references (Michel Foucault, Giorgio Agamben, Luigi Ferrajoli, Rui Cunha Martins, among others). It intends to show how Prado's theoretical and practical proposition, in addition to identifying the need for serious epistemological reflection about the preservation of the integrity of sources of evidence, broadly resumes discussions of the relation between evidence reliability, the pre-trial stage and the (rational) legal evidentiary reasoning.
\end{abstract}

Keywords: Epistemology, criminal procedure as a dispositive, chain of custody and evidence reliability.

\title{
1. Introducción
}

El presente artículo propone la construcción de una reseña del libro "La cadena de custodia de la prueba en el proceso penal”, de Geraldo Prado, lanzado en Brasil y en España, casi simultáneamente, en 2019. En el libro, Prado profundizó y amplió el enfoque que ya había hecho del tema en una 
Sobre "La cadena de custodia de la prueba en el proceso penal", de Geraldo Prado

obra anterior, publicada en el año 2014, en Brasil, con el título "Prova penal e sistema de controles epistêmicos: a quebra da cadeia de custódia das provas obtidas por métodos ocultos", ${ }^{1}$ un verdadero hito en la historia de la dogmática procesal penal brasilera, porque, hasta entonces, temas como la cadena de custodia - aquí entendida como dispositivo de garantía, mediante el registro y documentación de que un elemento de prueba es estrictamente el mismo que tiene relación con el hecho investigado y que no sufrió ningún tipo de modificación, deterioro, adulteración o contaminación durante toda su trayectoria, hasta la inserción en el proceso y la valoración judicial (Lopes Junior y Morais da Rosa, 2015) - y los debates sobre fiabilidad probatoria eran todavía poco o nada tratados por la doctrina nacional. ${ }^{2}$

Como la "Prova penal e sistemas de controles epistêmicos" nació de un dictamen elaborado por Prado, a pedido de los abogados que actuaban en la acción de Habeas Corpus 160662/RJ33 interpuesto ante el Superior Tribunal de justicia, se puede decir también que la discusión allí emprendida fue decisiva incluso para provocar un posicionamiento de la Corte, que, en la sentencia respectiva, abordó, de forma precursora en la jurisprudencia brasilera, cuestiones ligadas a la integridad de la prueba, habiendo enfrentado las consecuencias de la ruptura de la cadena de custodia de la prueba, ${ }^{4}$ con el "inédito reconocimiento explícito de la relevancia de activarse uno de los dispositivos del sistema de controles epistémicos, en el caso objeto de juicio, la cadena de custodia de determinadas pruebas digitales" (Prado, 2019, p. 11).

1 [N. de T.: "Prueba penal y sistema de controles epistémicos: la ruptura de la cadena de custodia de las pruebas obtenidas por métodos ocultos".]

$2 \mathrm{Al}$ menos en el ámbito del derecho procesal penal, ya que, por supuesto, en el campo de las ciencias forenses el tema ya era debatido desde hace algún tiempo, lo que demostraba incluso la preocupación de los peritos en materia penal por el tema, como se muestra en el artículo de Gomes y Azevedo, publicado en 2008 en la Revista Científica do Departamento de Polícia Técnica da Bahia (Gomes \& Azevedo, 2008, pág. 16-20).

3 Brasil, STJ, Habeas Corpus 160662/RJ, Sección Sexta, Ponente Ministra Assusete Magalhães, juzgado el 17/03/2014.

4 Véase al respecto, en particular, el Voto emitido por el Ministro Rogério Schietti, en la sentencia HC 160662/RJ, que mencionó específicamente el tema: "El hecho aquí, Sr. Presidente y demás colegas, es que hubo, en la expresión acuñada por el Prof. Geraldo Prado, una ruptura en la cadena de custodia de esta prueba. El Estado tenía el deber de preservar en su totalidad la prueba esencial, al parecer, para el descubrimiento de los hechos". 
En el libro publicado en el año 2019 y que es el objeto de este ensayo, sin embargo, el autor fue más allá. Presentó a los lectores aquello que denominó de "resultado de la intensificación de las investigaciones en la interfaz de la epistemología jurídica y la prueba penal, limitada, sin embargo, al supuesto del control epistémico específico de la cadena de custodia de las pruebas en el ámbito penal, una de las facetas del tema de la fiabilidad probatoria" (Prado, 2019, p. 9). Y entre las justificaciones presentadas para la nueva obra estaba el hecho de que la "perspectiva epistemológica" - hasta allí, muy poco difundida en la doctrina del proceso penal brasilero y que sirvió de base al primer libro- había sido "recibida con desconfianza por algunos sectores de la doctrina procesal penal, que hace tiempo se posicionaron en contra de algunas de las tesis sostenidas por Michele Taruffo" (Prado, 2019, p. 12), siendo esta la razón principal para que en este nuevo trabajo se aportara la "explicitación de premisas teóricas indispensables" a la comprensión de lo que Prado define "como función de garantía que la dimensión epistémica debe cumplir en el proceso penal contemporáneo" (2019, p. 12).

Para Prado (2019, p. 13), "las prácticas penales, entendidas como métodos de arbitraje o definición de la responsabilidad penal de alguien, se caracterizan por ser experiencias sociales productoras y reproductoras de conocimiento", existiendo "una dimensión epistémica ineludible, inherente a la tarea de investigar la existencia de una infracción penal y la eventual responsabilidad penal del imputado", y esta "dimensión epistémica de la prueba debe aumentar la garantía de la libertad”.

Sin embargo, como advierte el autor, no se debe descuidar el riesgo de que esta dimensión epistémica sea llevada al extremo y que inspire una desmedida obsesión por la búsqueda de la verdad, propiciando la construcción de un proceso penal autoritario (Prado, 2019, p. 13). Por eso es imprescindible advertir, como lo hace el autor, que el reconocimiento de que la averiguación de la verdad consiste en uno de los objetivos institucionales del proceso no significa "abrir las puertas del proceso a las pruebas obtenidas por medios ilícitos" ni mucho menos tolerar la actitud del juez que se asocia con la acusación e interviene como actor del campo de la seguridad pública (Prado, 2019, p. 13).

Conforme explica Prado (2019, p. 15), "buena parte de las reflexiones de este libro estarán dedicadas a estudios que se encuadran en el ámbito 
Sobre "La cadena de custodia de la prueba en el proceso penal", de Geraldo Prado

de la epistemología individual", consistente en el análisis del conjunto de condiciones que llevan a que un juzgador considere probado un hecho, lo que viene a constituirse como "tema nuclear de la legitimación política de la jurisdicción penal”. De hecho, con su enfoque, Prado llevó al contexto de la doctrina brasilera- que hasta entonces no había prestado la debida atención al tema- la comprensión de que las etapas de admisibilidad y de valoración de la prueba no se confunden y se desarrollan en momentos diferentes, debiendo la primera ser utilizada como filtro epistémico, para impedir que ingresen en el proceso (y que puedan ser posteriormente valorados) los elementos de prueba que no cumplen con los presupuestos mínimos de integridad y fiabilidad ${ }^{5}$.

Además de considerar las cuestiones epistemológicas que acompañan a la producción probatoria, el autor conecta postulados del proceso penal democrático (Estado de Derecho)- erigidos como fundamentos de la legitimidad de la persecución penal (principios del estado de inocencia, contradictorio y de defensa amplia)- para concluir que la prueba obtenida con violación a la cadena de custodia debe ser tratada como prueba ilícita (y no sólo en el campo de las nulidades), por lo que deberá ser inadmisible en el proceso.

Con esta propuesta, y por todo ello, no es exagerado decir que las dos publicaciones de Prado, en 2014 y en 2019, no sólo tuvieron la capacidad de abrir los ojos de la doctrina e incidir en el surgimiento de la jurisprudencia sobre el tema, sino también fueron decisivamente importantes para iniciar el debate sobre la necesidad de que la cadena de custodia fuese objeto de regulación en la legislación procesal penal brasilera, aún centrada en el

5 En cuanto a la relevancia de la cadena de custodia para la concepción del debido proceso penal, González (2013, p. 04), en relación al proceso penal español, aborda que: "no puede haber un juicio justo sin una actividad probatoria válida y de cargo capaz de enervar la presunción de inocencia. Siendo así, la relación directa de la evidencia con los hechos objeto de enjuiciamiento y su verosimilitud respecto de la prueba pericial son requisitos para su validez. A ese fin es necesario que se garantice que las evidencias que sirven de prueba estén relacionadas con los hechos y que no hayan podido ser alteradas o modificadas desde su recogida hasta su portación como prueba al juicio oral. En consecuencia, la cadena de custodia garantiza la verosimilitud de la prueba y por tanto se constituye en requisito necesario del proceso penal, sin el cual no puede hablarse de un juicio justo y con todas las garantías." 
Código de 1941. Se puede decir que, sin la repercusión generada por las dos obras de Prado, es improbable que el tema hubiera sido recordado como esencial en las iniciativas de la reforma legislativa que se sucedieron.

Sobre la cadena de custodia, el Instituto Brasilero de Ciencias Criminales realizó una importante contribución jurídica para que el tema fuera incorporado al Proyecto de Nuevo Código de Proceso Penal (Instituto, 2017), y, más recientemente, abordado en el texto de PL 10.372/2018, lo que dio lugar a, la denominada Ley Anticrimen, cuya promulgación resultó en la inserción de los arts. 158- A a 158-F en el antiguo CPP brasilero, trayendo, definitivamente, la regulación de la cadena de custodia al ordenamiento procesal nacional brasilero.

Con la entrada en vigor de la Ley n ${ }^{\circ} 13.964 / 19$ y con los nuevos artículos efectivamente incluidos en el Código, Brasil, aunque de forma tardía, especialmente considerando el panorama de otros países latinoamericanos $^{6}$, pasó a tener una disciplina legal de la cadena de custodia, lo que, sin embargo, consiste en un paso fundamental para un cambio de cultura de los actores jurídicos en relación a la manera en que evalúan y aplican el standard de admisibilidad de la prueba penal.

Con el cambio legislativo, el Código procesal penal brasilero incorporó, en el art. 158- A, el concepto de cadena de custodia, además de determinar el momento de su inicio $\left(\$ 1^{\circ}\right)$, definir la responsabilidad de la conservación de la prueba $\left(\$ 2^{\circ}\right)$ y establecer una definición legal de lo que se debe entender por rastros del delito $\left(\$ 3^{\circ}\right)$. En el art. 158-B, el legislador definió las distintas etapas del proceso de documentación de la cadena de custodia, abordando en cada uno de sus diez incisos lo que debe entenderse por reconocimiento, aislamiento, fijación, recolección, empaque, transporte, recepción, procesa-

6 La cadena de custodia se encuentra regulada, expresamente, en Venezuela, en su Código Orgánico Procesal Penal (arts. 187 y 188); en Colombia, en su Código de Procedimiento Penal (arts. 216, 254 a 266; y en los arts. 277 y 273); en Perú, aún de manera sucinta, en el Código Procesal Penal (art. 220, inciso V); en México, en los arts. 227 y 228 de su Código Nacional de Procedimientos Penales. Hay países, como Chile, donde, aunque el término cadena de custodia no aparece en el respectivo Código Procesal Penal, el Ministerio Público ha establecido protocolos sobre cómo debe ser preservada la identidad e integridad de los elementos de prueba. El Ministerio Público chileno elaboró un Reglamento sobre custodia de especies incautadas por el Ministerio Público. 
Sobre "La cadena de custodia de la prueba en el proceso penal", de Geraldo Prado

miento, almacenamiento y descarte de evidencias. En el art. 158-C, se cuidó, entre otras disposiciones, de establecer quién deberá realizar la recolección de los rastros (preferentemente el perito oficial), así como también de establecer la responsabilidad del organismo central de pericia oficial para detallar los protocolos necesarios para el cumplimiento de las directrices de la ley.

En el art. 158-D, el legislador dispuso la forma en que se almacenan los rastros y también estableció reglas para colocar y quitar los sellos de los embalajes. En el art. 158-E se sancionó, de manera similar a lo previsto en el Código Venezolano (art. 188), la necesidad de creación de centros de custodia, vinculados a la estructura de los Institutos de Criminalística, con la responsabilidad de proceder al resguardo y control de los elementos de prueba. Finalmente, el art. 158-F dispuso sobre el régimen de almacenamiento de los rastros en los centros de custodia, así como reguló cómo se deberá proceder cuando el centro no dispusiera de espacio o condiciones para almacenar determinado material.

Dado que la Ley ${ }^{\circ} 13.964 / 19$ fue sancionada en una fecha posterior (25 de diciembre de 2019) tras el lanzamiento de "La cadena de custodia de la prueba en el proceso penal", Prado no abordó el tema con una perspectiva "de lege lata", lo que sin duda será hecho en una próxima edición, como ya se anunció, incluso en sus redes sociales (Prado, 2020). Hasta entonces, sin embargo, la destacada obra ofrece un amplio material de estudio, no sólo sobre la cadena de custodia, sino también sobre la prueba en el proceso penal brasilero, sobre todo por la forma en que se desarrollaron las ideas en el libro, con sus 5 capítulos estructurantes, además de los tópicos dedicados a la presentación de la obra (capítulo 1) y a la conclusión (capítulo 6).

El profesor recién retirado de la Facultad Nacional de Derecho aborda, en el capítulo 2, la relación entre prueba y verdad (de la verdad a la prueba: los caminos cruzados del derecho y de la epistemología jurídica en la política del proceso penal). Adopta la concepción de que la verdad debe actuar como indicador epistémico y presenta la noción de proceso como dispositivo - en la línea propuesta por Rui Cunha Martins (2012). En el capítulo 3 , se analiza el modelo de proceso requerido por el Estado de Derecho y los respectivos supuestos que legitiman la persecución penal. En el capítulo 4, desarrolla una reflexión sobre el dispositivo procesal probatorio y el sistema de controles epistémicos. En el capítulo 5, discute sobre la relación entre 
la fiabilidad probatoria y la cadena de custodia de las pruebas, concluyendo que la violación de la cadena de custodia resultará en la ilicitud de la prueba, con su consecuente inadmisibilidad en el proceso.

En el transcurso del presente texto, por lo tanto, serán sintetizadas y analizadas las ideas y propuestas desarrolladas por Prado, respetando, en la medida de lo posible, la estructura y orden de presentación de los temas planteados por el autor del excepcional libro "La cadena de custodia de la prueba en el proceso penal".

\section{Prueba y verdad: (re)definiendo el lugar de la verdad en el proceso penal. Verdad como indicador epistémico y las epistemologías}

Destaca Prado (2019, p. 21) que, en las democracias, la "legitimidad del ejercicio del poder punitivo está condicionada por el valor de verdad reconocido en la sentencia", pero esto no debe, según el autor, "conducir al equívoco de suponer que realidad y verdad, desde el punto de vista de la epistemología, son la misma cosa y de que el juez, munido de un aparato intelectual refinado por años de práctica, está en condiciones de tener acceso a la realidad o al modo como ésta se presentó en el mundo de la vida".

Según Prado (2019, p. 22), "el juicio sobre los hechos no opera en la dimensión de la realidad, sino en una controversia sobre el pasado que, por ser especial y físicamente inaccesible, plantea el problema de la verdad de las proposiciones al respecto", extrayendo de la epistemología la noción de que "el juicio de verdadero o falso no incide sobre el hecho en sí, sino sobre la proposición/afirmación/enunciado sobre la existencia del hecho".

Según esta definición, resulta claro que el proceso no conseguirá promover el conocimiento total de aquello que sucedió. Es una actividad cognitiva fragmentaria de captación de los eventos empíricos. Se fragmenta el poder del conocimiento ya en la producción enunciativa de la norma jurídica, que selecciona, de manera abstracta, las limitaciones fácticas que considera importantes y válidas para el Derecho.

Ya en la década de 1950, Jose Guarnieri (1952, p. 19), profesor de la Universidad de Parma, había notado que "toda la materia procesal se mani- 
Sobre "La cadena de custodia de la prueba en el proceso penal", de Geraldo Prado

fiesta no 'in se', sino en forma de afirmaciones- entendidas en el amplio sentido como declaraciones, conclusiones, valuaciones, - de los sujetos procesales. [...] De otro modo faltaría a los sujetos interesados hasta la posibilidad misma de entenderse."

De hecho, el proceso se presenta como un universo lingüístico ligado al empírico, a situaciones que, frente la concreción consuetudinaria de la vida, provocan impacto jurídico-penal. Las actividades cognitivas procesales navegarán, invariablemente, en signos lingüísticos, reproduciendo significados y construyendo muchos otros. Dependiendo de la intensidad dialéctica que marque la expresividad procesal de los sujetos, pueden surgir nuevos conceptos para antiguos signos y, eventualmente, nuevos signos pueden resultar de la transformación de la cultura procesal ${ }^{7}$.

La verdad, como posibilidad factible en el proceso penal, debe comprender la dimensión lógica- lingüística del lenguaje como determinante de la intersubjetividad y la diversidad social. Es, a través del lenguaje, que la epistemología se derrama sobre el proceso penal, haciéndolo ser entendido como un intercambio de diversas agendas cognitivas (posibilidades de conocimiento de la cuestión criminal) presentadas por dichos sujetos procesales.

Prado (2019, p. 32-33) destaca que, al colocar la verdad como indicador epistémico, su "punto de partida es garantista", centrado en el axioma "nula poena sine iudicio" (no hay pena sin proceso), que Luigi Ferrojoli adopta como esencial en una perspectiva de estricta jurisdicción de la sanción penal. Según Prado, el proceso penal no tendría un valor en sí mismo. Debe ser analizado por una visión que vincule epistemología y normatividad, confiriéndole una legitimidad compatible con el moderno Estado de

7 Haack (2015, p. 129; p. 160): "el crecimiento del significado - con lo que me refiero no solo al hecho de que las palabras adquieren nuevos significados, sino también a la pérdida de sus antiguas connotaciones, así como a la acuñación de nuevos términos o cooptación de términos antiguos para expresar nuevos conceptos y distinciones-, es solo un aspecto de este fenómeno mucho más amplio y enormemente más complejo de la evolución y del desarrollo de las lenguas. [...] los cambios y alteraciones en el vocabulario de las ciencias naturales contribuyen al progreso en la medida que se ajustan mejor a las especies reales de cosas del mundo. No hay duda de que la referencia importa. Pero, como mi idea es que los significados de los términos científicos crecen y cambian con la evolución del conocimiento, asumo que tienen significados y así, obviamente, resisten a la asimilación de términos de especies a designadores estrictos". 
Derecho. En el proceso penal, se debe proporcionar el mejor conocimiento posible de los hechos relevantes para que haya una decisión penal legítima, moldeada en la relación entre prueba y verdad.

En este panorama, sobresale, con mucha pertinencia, la advertencia de Prado (2019, p. 22-25) de que su propuesta en colocar la verdad como indicador epistémico del proceso penal no pretende retomar la época medieval de la verdad absoluta, nutrida por la línea filosófica de la Ontología, que representaba la posibilidad de captación total del mundo exterior, como si el individuo, con sensaciones e impresiones, no pudiese interferir en la construcción de esta realidad al traducirla, por medio del lenguaje, al proceso penal. El autor referido destaca que los jueces no están dotados de “superpoderes epistémicos" (2019, p. 27).

La noción de verdad como indicador epistémico estimularía una comprensión ética del proceso penal, establecida no sólo en la prohibición de pruebas ilícitas, taxativamente prevista en la Constitución Brasilera (art. $5^{\circ}, \mathrm{LVI}$ ), sino atenta a una racionalidad epistemológica (diversos razonamientos inferenciales, construcción de hipótesis alternativas, uso de conocimientos científicos), a fin de que los argumentos probatorios tengan la fiabilidad necesaria para obtener una determinación correcta y justa de los hechos.

Taruffo (2016, p. 141-143; p.160-161) también valora la dimensión epistémica del proceso, cuando expresa que la verdad, en el proceso, es la que ocurre en un contexto jurídico. Para él, al verificarse la efervescencia teórica de los enfoques que requieren una aproximación de la Epistemología al Derecho (Larry Laudan, Alvin Goldman y Susan Haack), es posible definir el proceso como un modelo epistemológico de conocimiento de los hechos con base en la prueba. Para esta manera de pensar, la epistemología materializaría el concepto de proceso justo, no más limitado al cumplimiento ritual de las garantías procesales. La decisión justa debe también abarcar una correcta interpretación de la norma jurídica utilizada como criterio de la decisión y tener como fundamento una verdadera investigación de los hechos del caso, evitando errores judiciales.

Ferrer Beltrán (2007, p. 20-21), al enfatizar la relación teleológica entre prueba y verdad, considera que la verdad es el objetivo fundamental de la actividad probatoria en el proceso, aunque coexiste con otras finalidades 
Sobre "La cadena de custodia de la prueba en el proceso penal", de Geraldo Prado

procesales, que pueden limitar esta actividad ( $v . g$. garantía de la duración razonable del proceso ${ }^{8}$ ). Para él, la noción de verdad como correspondencia sería la que serviría a las finalidades del Derecho, porque traduce que los enunciados fácticos probados en el proceso, los cuales se refieren a condiciones descriptas en la norma, tienden a corresponder a lo que sucedió en la realidad. De esta forma, se permite, con este referencial de verdad, que las consecuencias jurídicas previstas por la norma sean aceptadas con seguridad jurídica.

Por lo tanto, para el citado autor (2017, p. 29-32), la noción de prueba está ligada a la aceptabilidad de la verdad de un enunciado, que se declara probado a partir de la existencia de un contexto suficiente de elementos de juicio a su favor. Para maximizar las probabilidades de que la determinación judicial de los hechos corresponda con la verdad, las metodologías e instrumentos de la epistemología general incidirían en la valoración de la prueba, dentro de lo que se denomina libre convencimiento motivado ${ }^{9}$.

Existen varias construcciones posibles, sistemáticas y teórico-prácticas, para esta relación entre epistemología, prueba, verdad y proceso ${ }^{10}$. Tra-

8 Nicolitt (2014, p. 40) recuerda que "la cuestión temporal surge en cuanto a la forma de la decisión (decisión formalmente justa). Una decisión justa no puede ser precipitada e irreflexiva, incompatibles con la actividad jurisdiccional, tampoco puede tener la morosidad destructiva de la efectividad de la jurisdicción". Como se ve, la relación entre la epistemología aplicada al proceso penal y el tiempo del proceso es una relación de constante ponderación concreta.

9 [N. de T.: En español mejor conocido como "sana crítica racional"].

${ }^{10}$ Gascón Abellán (2010, p. 43), al proponer una epistemología moderadamente realista, percibe que "podría decirse que en los planteamientos más reflexivos de la actualidad se aprecia una tendencia a concebir el juicio de hecho como «la elección de la hipótesis racionalmente más atendible entre las distintas reconstrucciones posibles de los hechos de la causa; en consecuencia, la «verdad de los hechos» nunca es absoluta, sino que viene dada por la hipótesis más probable, o sostenida por mayores elementos de confirmación". Relacionando verdad, criterios epistemológicos y jurídicos, dice Daniela Accatino (2016, p. 7): "se trata de notar que la cuestión de la suficiencia de las pruebas no está sujeta sólo a criterios epistémicos sino también a criterios jurídicos, establecidos a través de los estándares de prueba, que pueden fijar umbrales de mayor o menor exigencia sobre la base de consideraciones relativas a la distribución justa del riesgo de error entre las partes en las distintas clases de procesos". En la presentación de Quaestio Facti (Ensayos sobre prueba, causalidad y acción), González Lagier (2019, p. 5) propone una "Teoría de la Prueba judicial que reúna dos condiciones: a) que esté construida desde los hechos, esto es, a partir de los 
jimos algunas líneas introductorias del pensamiento de Ferrrer Beltrán, por ser uno de los pensadores españoles del derecho probatorio que ha despertado, en Brasil, gran interés en las discusiones sobre la prueba tanto en el proceso civil como en el proceso penal. Y, también, por tener una sistematización de pensamiento que, al defender- desde la perspectiva de la valoración racional de la prueba- la verdad como correspondencia, no retoma la ontología de la verdad real. De hecho, es exactamente lo contrario. Esta advertencia se extiende también a la noción de Prado sobre la verdad como indicador epistémico del proceso, que dialoga con las concepciones de verdad desarrolladas por Taruffo y Ferrer Beltrán ${ }^{11}$.

Dicho esto, Prado (2019, p. 33) afirma que la "adopción de la categoría 'verdad' como indicador epistémico es, por lo tanto, funcional al fin de dotar al proceso de una meta y simultáneamente definir los límites éticos, políticos y jurídicos de la actividad de investigación de la verdad material". Expone que, al admitirse la existencia de varias teorías de la verdad (pragmáticas, fenomenológicas, racionales, de la coherencia, de la correspondencia semántica y no semántica, hermenéuticas e intersubjetiva- 2019, p. 24), esta diversidad teórica "no constituye un obstáculo para que se atribuya al proceso la calidad de método epistémico de determinación de la responsabilidad penal" (2019, p. 33).

Por lo tanto, para Prado (2019, p. 32-33), la verdad como indicador epistémico es una verdad como garantía del proceso penal justo y equitativo, que se aparta de la concepción tecnicista que enmarca el proceso penal como un mero instrumento del Derecho Penal. La verdad como

problemas planteados por éstos (la definición de los distintos tipos de hechos, el problema de su conocimiento, la cuestión de su objetividad y su entrelazamiento con cuestiones interpretativas, etc.), y no desde las normas (esto es, que no se limite a ver los problemas de prueba como problemas de interpretación de las normas jurídicas que regulan la actividad probatoria). Y b) que esté abierta a las investigaciones realizadas desde el campo de la filosofía (esto es, que proyecte sobre el problema de la prueba judicial las conclusiones de la epistemología, la filosofía de la acción, la ética, etc.)."

11 En Brasil, Badaró (2019, p. 14-21), al pensar sobre las interrelaciones de la epistemología y la prueba penal, destaca que está alineado a los pensadores que combaten la veriphobia. Entiende que la verdad es condición necesaria, pero no suficiente, para que se alcance una decisión justa. Para él, el proceso, como espacio procedimental cognitivo, limitado por reglas de admisión y producción probatoria, produce una verdad jurídicamente condicionada. 
Sobre "La cadena de custodia de la prueba en el proceso penal", de Geraldo Prado

maximización protectora de los derechos y garantías fundamentales hace que el procedimiento penal sea interpretado para proporcionar una decisión justa en el proceso penal, tomando siempre como punto de partida, para la obtención de esta verdad que se produce en contexto jurídico, el respeto estricto al principio de presunción de inocencia.

En este contexto, si, como dice Rui Cunha Martins (2012, p. 71), la verdad es una cuestión de lugar, de giro dinámico y recurrente entre posiciones procesales y sistémicas, con injerencia de los diseños normativos previstos para las instituciones que actúan en el proceso penal, se piensa que, al afirmarse la verdad como indicador epistémico, se reposiciona tanto la noción de verdad como la propia concepción metodológica del proceso penal. La epistemología jurídica pasa a llenar el contenido jurídico del concepto de debido proceso penal.

No se trata sólo de una conversación interdisciplinaria con la epistemología. La epistemología jurídica aplicada al proceso constituyó un nuevo tamiz para defender el debido proceso penal, junto con la necesidad de preservación de las garantías fundamentales y del control de convencionalidad de dispositivos procesales. La epistemología jurídica invita a una relectura estructural del proceso penal, desde la etapa de investigación preliminar hasta la última etapa recursiva del proceso, con la intención de permitir una comprensión amplia de las cuestiones fácticas y jurídicas dadas en el proceso.

A través de la epistemología, las cuestiones de hecho y de derecho se interrelacionan en diferentes grados de intensidad, con momentos de indistinción conceptual, lo que, comúnmente, no es admitido por la dogmática procesal clásica, acostumbrada al análisis estricto de las normas de procedimiento probatorio (Ubertis, 2020, p. 70). Andrés Páez (2015, p. 3) recuerda que la epistemología propone una nueva mirada sobre el derecho probatorio, cuando plantea la exploración de fundamentos filosóficos (lógica, gramática, retórica, estadística, probabilidad, psicología, etc.) en este campo del derecho procesal.

Páez (2015, p. 3) informa, también, que la expresión epistemología jurídica es ambigua, usada para referirse a las posibilidades de conocimiento del derecho (teorías del conocimiento aplicables al derecho), además de asumir una nueva connotación, interdisciplinaria, para referirse, actual- 
mente, al derecho probatorio, pudiendo, en esta acepción, denominarse filosofía de la prueba jurídica.

Al proponer una epistemología jurídica específicamente aplicable al proceso penal, flexible en recibir influencias de la propia dogmática procesal penal, Matida (2020, p. 5) explica que la epistemología jurídica es un desdoblamiento de la epistemología general y que "la epistemología, como parte de la filosofía, es el estudio del conocimiento. Cuáles son las condiciones necesarias y suficientes del conocimiento, cuáles son sus fuentes y límites, bajo qué circunstancias el sujeto está autorizado a decir que conoce algo, etc. ${ }^{12 ”}$.

Con estas aclaraciones, cuando se dice aquí que la epistemología jurídica constituye el debido proceso penal, también se debe señalar que no todo ha de ser pensado desde esta nueva etapa del repositorio de conocimientos jurídicos del proceso penal. Cabe preguntarse: ¿qué epistemología jurídica? Al igual que ocurre con la Criminología, que no se contenta con pronunciarse en singular -son Criminologías-, existen Epistemologías potencialmente jurídicas (individual, social, objetiva, subjetiva) que pueden constituir el proceso penal.

Por esto, si la propuesta epistemológica es posibilitar una determinación positivamente calificada (justa) de los hechos en un contexto jurídico-procesal - propuesta que incluye la verdad como indicador epistémico-, se debe buscar una concepción de epistemología jurídica, que, atenta a la constante necesidad de preservación de los derechos y las garantías fundamentales procesales, permita un amplio y responsable aporte de argumentos probatorios al proceso penal, para que los razonamientos probatorios de los sujetos procesales, en especial del juez, se realice a partir de premisas fácticas sólidas, resultantes de dinámicos y variados razonamientos inferenciales, los que, dependiendo del momento probatorio en que el proceso se encuentre, no siempre son fáciles de identificar.

Y más: que la (s) epistemología (s) aplicable (s) al proceso penal brasilero reconozca la tradición histórica de autoritarismo procesal, que interfiere en la conformación práctica de los sistemas procesales, llevados a los

12 Texto en prensa, gentilmente cedido por la profesora Janaína Matida, cuyo título es Epistemología Jurídica aplicada ao processo penal: reflexões sobre os poderes probatórios do julgador na realidade brasileira. 
Sobre "La cadena de custodia de la prueba en el proceso penal", de Geraldo Prado

sótanos inquisitivos de la praxis criminal cotidiana del sistema de justicia, problemática que por regla general, no pide permiso para la distinción académica excesivamente teórica entre sistema acusatorio e inquisitorio. En este paso, la advertencia de Prado (2019, p. 37) es más que válida, en el sentido de que "la consciencia del predominio de elementos discursivos más próximos de la ‘voluntad de poder〉 de lo que del propósito de justificación por la comprobación de los hechos constituye condición previa para la ruptura con el dispositivo inquisitorial".

Sobre la multiplicidad de epistemologías jurídicas, Prado (2019, p. 15-19) se vale de algunos conceptos propuestos por Danny Marrero, profesor de la Universidad Javeriana. Va más allá de estos conceptos, en realidad. Identifica la articulación epistemológica - no es una única epistemología jurídica - que considera aplicable al proceso penal y establece, a partir de ella, una nueva clave de lectura para entender el proceso penal como dispositivo, concepto que será abordado en el tópico siguiente.

En síntesis, Marrero (2015, p. 15-33) aborda la crítica a la epistemología jurídica individual (conjunto de condiciones que llevan a que un juzgador considere probado un hecho) y, en cierto modo, a la social (procesos cognitivos relacionados con diseños institucionales), considerándolas de alcance incompleto para permitir un conocimiento adecuado de los hechos jurídicos. Propone un modelo de epistemología integrado al Derecho, que respete el proceso de interacción entre el individuo (operador del sistema jurídico) y las instituciones jurídicas, porque son en estas interacciones que los procesos cognitivos se desarrollan y se vuelven valiosos en la determinación de los hechos en un contexto jurídico- procesal.

Para este autor, la institución interfiere con el modelado cognitivo del individuo (posibilidades de conocer la realidad). Los individuos también interfieren en los procesos cognitivos institucionales. Esta reciprocidad de posibilidades cognitivas constituye las agencias epistémicas, que están interesadas en las funcionalidades epistemológicas propuestas a los operadores jurídicos en razón de sus roles procesales. Al señalar este aspecto del Derecho, visto como sistema cognitivo, Marrero (2015, p. 32) presupone que el "derecho impone agendas cognitivas, o programas de acciones, a los agentes jurídicos. Si esto es correcto, la epistemología jurídica debería evaluar dichas agendas". 
A pesar de la inclinación conciliadora de Marrero (2015, p. 15-33), que propone una Epistemología Jurídica sobre agendas cognitivas del Derecho, debiendo ser integradas las epistemologías individual y social, Prado (2019, p. 17), aun cuando reconoce la utilidad teórico-práctica de este modelo epistemológico conciliador, señala su insuficiencia cuando dice que el libro abarca "nociones de epistemología subjetivista, ya sea adhiriendo a la tesis del proceso como dispositivo, en la línea de pensamiento de Rui Cunha Martins" y sabiendo que, "si en todas partes una epistemología jurídica puramente objetiva no se ha hecho realidad, es porque el sistema penal selectivo se ha impuesto, con su significativa gama de prejuicios".

Prado (2019, p. 17) sugiere que, incluso en el campo de las Epistemologías, no se puede perder la lectura crítica, la mirada sobre el terreno social e histórico en que incidirá determinado modelo de epistemología. Las Epistemologías Subjetivas, entendidas por Prado como Epistemologías del Sur ${ }^{13}$, serían aquellas que permiten conocer cómo se producen las continuas posturas excluyentes y epistemicidas de un determinado saber hegemónico en relación a las líneas de diversidad social del saber humano, algo muy común en el Sur global.

En el escenario de las Epistemologías del Sur, Boaventura de Souza Santos (2013, p. 31), al visualizar la formación de una ecología de saberes, centrada en la consistencia epistemológica de conocimientos heterogéneos y propositivos ${ }^{14}$, analiza que:

${ }^{13}$ Pueden ser vistas también como Epistemologías "Críticas", "Periféricas", "Marginales", en el sentido de que cuestionan una concepción de producción del conocimiento científico que se refiere, exclusivamente, a una razón insípida, eurocéntrica y norteamericanizada, que no consigue absorber las longitudes y latitudes que diversifican la propia razón humana, a partir de las experiencias históricas de las sociedades periféricas. Serían Epistemologías contra-hegemónicas. Por otro lado, Gascón Abellán (2010, p. 36-37) utiliza la denominación Epistemología Subjetivista para referirse a las prácticas reprochables del decisionismo judicial, al intuicionismo judicial en el momento de la decisión, lo que elimina la necesidad de una valoración racional de la prueba. La referida autora dice que "uno de los reflejos jurídicos más devastadores de las epistemologías subjetivistas lo constituyen, en efecto, ciertas tendencias antiformalistas para las que la prueba no es primordialmente averiguación y fijación de los hechos, sino una actividad esencialmente subjetiva y por ello irracional o incontrolable."

${ }^{14}$ Al priorizar una filosofía de la liberación, Dussel (2011, p. 98-99) advierte que "la praxis de dominación es la acción injusta. Es la afirmación práctica de la totalidad y su proyecto, es la realización óntica del ser. Su efectuación alienante. El señor ejerce su poder actual sobre 
Sobre "La cadena de custodia de la prueba en el proceso penal", de Geraldo Prado

en cada uno de los dos grandes dominios - la ciencia y el derecho - las divisiones llevadas a cabo por las líneas globales son abismales en el sentido en que eliminan definitivamente cualquier realidad que se encuentre del otro lado de la línea. Esta negación radical de copresencia fundamenta la afirmación de la diferencia radical que, desde este lado de la línea, separa lo verdadero de lo falso, lo legal de lo ilegal, El otro lado de la línea comprende una vasta gama de experiencias desperdiciadas, invisibilizadas, al igual que sus autores, y sin una localización territorial fija. En realidad, como anteriormente referí, originalmente existió una localización territorial y esta coincidió históricamente con un territorio social específico: la zona colonial.

Prado (2019. p. 37), por tanto, llama la atención sobre el hecho de que la construcción epistemológica del proceso penal, adoptando la verdad como indicador epistémico, tiene como obstáculo el "alto grado de colonización inquisitorial del proceso penal brasilero", en el que las "condenaciones se fundamentan en pruebas a pesar de no estar basadas en pruebas". Destaca que, junto a una epistemología individual (la construcción de la decisión judicial), una propuesta de Epistemología del Sur (Subjetiva), que respete el proceso penal como modelado institucional cognitivo (epistemología social), debe preocuparse por:

cuestiones relacionadas a la protección del interés vital de las personas que viven bajo el estigma incriminatorio, y que bajo tal estigma están sujetos a un "acomodo funcional" a los estratos sociales más vulnerables, poniéndose en resalto temas como la protección de su domicilio, la garantía de su integridad física y psicológica contra la tortura, y la preservación de las condiciones de su autodeterminación informativa, además del derecho a participar activamente de un proceso penal que no esté codificado lingüísticamente hasta el punto de necesitar ser descifrado [no participo activamente de aquello que no puedo entender] sólo son pasibles de formularse si las relaciones de poder que expresa el fenómeno penal pudieran ser captadas mediante herramientas teóricas adecuadas. (Prado, 2019, pág.35).

el siervo por medio del obrar opresor. Es la mediación del sistema como formación social y por medio de la cual su estructura resiste y persiste" 
Es a partir de este diálogo fluido entre epistemologías individual, social y subjetiva que se puede obtener una mayor democraticidad en el proceso penal. Sin embargo, si la praxis procesal penal sigue siendo inquisitiva, las iniciativas epistemológicas para una mejor determinación de los hechos serán intentos de atajos democráticos perdidos en esta densidad inquisitorial, que sigue estructurando la mentalidad de los operadores jurídicos. Con cierto pesar, en este punto, hay que recordar a Alberto Binder (2004, p. 1) cuando dice que la historia de la legalidad en América Latina es la historia de la debilidad de la ley.

Los movimientos de reformas procesales penales -especialmente cuando priorizan la realización de un debido proceso penal en países de tradición histórico-política autoritaria, como Brasil- suelen encontrar resistencia política-criminal (conservadora y autoritaria) de movimientos de contrarreforma procesal penal, provenientes, inclusive, del propio poder legislativo y de la jurisprudencia. Es de esta forma que se presenta la debilidad de la legalidad en América Latina.

Por todo ello, la epistemología jurídica, con su aliento revitalizante sobre un tema fundamental para el sistema acusatorio procesal - la prueba penal -, sufrirá una falta inicial de aclimatación espontánea en el proceso penal, el cual tiende a sentirse más cómodo con la vulgarización del arte retórico en decisiones penales que simulan, en sus motivaciones, un correcto acierto de los hechos.

No por esto dejará, la Epistemología, de anunciar al proceso penal que existen nuevas formas de realizar el debido proceso, que se regirá por aportes teóricos y empíricos de una metodología de producción de conocimiento, que respete las racionalidades lógicas y científicas, lo que no se confunde con ausencia de sensibilidad analítica con respecto a la cuestión criminal. Y la obra de Prado es, sin duda, una buena señal en este sentido.

\section{Proceso penal como dispositivo}

¿Qué es un dispositivo? En una entrevista realizada por Alain Grosrichard sobre el primer volumen de La historia de la sexualidad, Michel Foucaullt (2018, p. 364) responde que, al utilizar el término dispositivo, intenta demar- 
Sobre "La cadena de custodia de la prueba en el proceso penal", de Geraldo Prado

car un "conjunto heterogéneo que engloba discursos, instituciones, organizaciones arquitectónicas, decisiones reglamentares, leyes, medidas administrativas, enunciados científicos, proposiciones filosóficas, morales y filantrópicas”.

El dispositivo se revelaría en la interacción entre lo dicho y lo no dicho, en una suerte de juegos de poder que constituyen saberes, implican cambios de posición y de funciones de los elementos discursivos y no discursivos (Prado, 2019, p. 17). El dispositivo "es algo mucho más general que comprende la epistémè. O más bien, que la epistémè es un dispositivo específicamente discursivo, a diferencia del dispositivo, que es discursivo y no discursivo, con sus elementos mucho más heterogéneos (Foucault, 2018, p. 365-367)”.

Giorgio Agamben (2009, p. 46-47), filósofo que tiene algunos escritos sobre el pensamiento de Foucault ${ }^{15}$, va más allá de la noción foucaultiana de dispositivo para entenderlo como una heterogeneidad de elementos que provocan, en la coyuntura capitalista, la dessubjetivación del sujeto, convirtiéndolo solo en un número a ser controlado.

El dispositivo, en Foucault, al someter al individuo, le quita la primera subjetividad, sustituyéndola por una subjetividad artificial, ilusoria, resultante de los juegos de poder que imperan en el propio dispositivo. Agamben (2009, p. 48-49) radicaliza esta dimensión, al decir que el dispositivo ni siquiera produce una subjetividad ficticia para el individuo. Lo convierte en algo espectral, completamente despojado de sí. En esta dimensión, las sociedades contemporáneas se presentan "como cuerpos inertes atravesados por gigantescos procesos de dessubjetivación que no corresponden a ninguna subjetivación real".

Entender el proceso criminal como un dispositivo es visualizarlo en una multiplicidad de interacciones entre poder, política, dogmática, epistemolo-

15 En texto que intenta responder la pregunta $O$ que é um paradigma?, Agamben (2019, p. 13-14), al trazar un paralelo crítico entre el método de la arqueología foucaultiana y la concepción de paradigma instaurada por Tomas Kuhn, señala que "una de las orientaciones más más constantes de investigación de Foucault es el abandono del abordaje tradicional del problema del poder, basado en modelos jurídicos e institucionales y en categorías universales (el derecho, la teoría de la soberanía), en pos de un análisis de los dispositivos concretos mediante los cuales el poder penetra en los propios cuerpos de los súbditos y gobierna sus formas de vida". 
gía y tantos cuantos sean los elementos discursivos y no discursivos que lo conformen. Esta es la propuesta conceptual de Prado (2019, p. 37) que, al reconocer las influencias filosóficas antes mencionadas, adopta la definición de proceso penal como dispositivo desarrollada por Rui Cunha Martins:

el proceso, cualquier proceso, como dispositivo articulador de elementos de diversa índole, uno de los cuales puede ser el valor verdad, y cuyas modalidades de interacción son tanto regulares como imprevisibles, respondiendo básicamente a criterios de conectividad. Es sobre esta multiplicidad que invierte, en un determinado momento (más precisamente: en el momento en que esta dinámica procesal se constituye un proceso al servicio de algún ícono específico: proceso histórico, proceso económico, proceso constituyente, proceso administrativo, proceso civil, proceso penal...), una necesidad de sistema, correspondiente al deseo de imponer una estructura dotada de sentido a la dispersión constitutiva de los elementos procesales. En este punto, se trata de direccionar la conectividad y dirigirla hacia un fin. (Martins, 2012, pág.73).

Prado, al compartir la percepción teórico-práctica que conceptualiza el proceso penal como dispositivo, no deja de reconocerlo como un modelo del proceso constitucionalmente previsto para contener el Poder Punitivo $^{16}$. No reserva al proceso penal un destino pesimista, de infinita inquisitoriedad. Al asumir la heterogeneidad procesal, sabe que la praxis criminal ofrece diferentes ejemplos en que los elementos no discursivos tienden a sofocar la estructura procesal acusatoria. Y, precisamente para evitar esta gubernamentalidad inquisitoria en el proceso penal, la verdad como indicador epistémico proporcionará "la introducción de métodos y prácticas probatorios de verificación de los hechos que puedan ser efectivamente confrontados de manera contradictoria y probados en relación a su potencial para explicar la realidad" (Prado, 2019, pág.39).

${ }^{16}$ De acuerdo con Roxin (2000, p. 10), "el Derecho procesal penal es el sismógrafo de la Constitución del Estado! Reside en ello su actualidad política, la cual significa, al mismo tiempo, que cada cambio esencial en la estructura política (sobre todo una modificación de la estructura del Estado) también conduce a transformaciones del procedimiento penal." 
Sobre "La cadena de custodia de la prueba en el proceso penal", de Geraldo Prado

La verdad como indicador epistémico, en un proceso penal pensado críticamente como dispositivo, permite una amplia corrección dogmática y epistemológica del proceso penal. Confiere mayor legitimidad democrática al ejercicio del poder persecutorio y penal, lo que contempla, satisfactoriamente, un modelo constitucional de proceso penal, que traza, procesal y sustancialmente, los postulados del Estado Democrático de Derecho.

Cabe señalar que el Garantismo, de Luigi Ferrajoli, es también un marcador teórico del análisis de Prado sobre la cadena de custodia, instituto procesal que debe cumplir, de acuerdo con la epistemología, la lógica de máxima preservación de los derechos y las garantías fundamentales. Repítase lo dicho por Prado (2019, p. 31): "el punto de partida es garantista", para que la relación entre verdad, prueba y proceso penal sea "condición de posibilidad de un proceso penal conformado por mandatos del estado de derecho y en estos términos la presunción de inocencia constituye el principio rector del proceso penal".

En este punto, recuérdese que Luigi Ferrajoli es también un grande epistemólogo ${ }^{17}$ y que la teoría del garantismo penal propone, con sus axiomas, una relación entre Derecho y Razón, en la cual la palabra razón se presenta en tres sentidos. La razón en el derecho (epistemología del derecho), la razón del derecho (axiología y política) y razón de derecho penal (ciencia penal). Por esto, el ámbito académico del derecho probatorio, que hoy se encuentra fecundo y revitalizado por la epistemología, ya había experimentado una primera ola epistemológica en el proceso penal, hace casi 20 años ${ }^{18}$, con la recepción de la Teoría del Garantismo Penal en Brasil ${ }^{19}$.

17 En este sentido, véase la obra de Ferrajoli (2013).

${ }^{18}$ En realidad, Prado adhirió al Garantismo Penal, de Luigi Ferraojoli, desde su disertación de maestría (1998), publicada como libro, cuyo título es Sistema Acusatório. A conformidade constitucional das leis processuais penais. Cítese el siguiente pasaje del libro mencionado: "vale recordar la advertencia de Ferrajoli, para quien, considerando la diferenciación de los distintos niveles de normas agregadas al ordenamiento jurídico (leyes, reglamentos, resoluciones, etc.) es común observar en el nivel normativo superior (la Constitución de la República) un estado de cosas refutado por disposiciones de niveles normativos inferiores (leyes y hasta reglamentos), y de la práctica judicial, dando lugar a la tendencia de los primeros a ser ineficaces e ilegítimos los segundos" (Prado, 2006, p. 7).

19 "En esta perspectiva el modelo penal garantista equivale a un sistema de minimización del poder y de maximización del saber judicial, en cuanto condiciona la validez de las decisiones 
En este panorama, Prado (2019, p. 42) realiza algunas observaciones, ajustes dogmáticos e interpretativos, para que el proceso penal (disposición procesal) sea entendido como "entidad epistémica regulada, de acuerdo con el concepto abierto constitucional del debido proceso legal". Por lo que se lee de la obra de Prado, su pensamiento aparece como favorable a la máxima potencialización interpretativa de la presunción de inocencia, que puede alcanzar, según pensamos, a un estado de metanivel procesal ${ }^{20}$. Utilizando la clasificación propuesta por Ávila (2005, p. 93), en su Teoría de los Principios, nos permitimos decir que "no considerar a una persona culpable hasta que la sentencia condenatoria se encuentre firme (art. 5, LVII, CF / 88 )" es un texto jurídico que autoriza la construcción de tres dimensiones normativas: a) norma-principio: el máximo respeto al estado de inocencia de una persona es el estado ideal de la acusación procesal; b) norma-regla: impone reglas de tratamiento procesal a la persona acusada como si fuera inocente (por ejemplo, prisión preventiva y uso de esposas en situaciones excepcionales) y también puede ofrecer una excelente regla de juzgamiento para resolver una duda final sobre cuestiones fácticas relevantes - in dubio pro reo ${ }^{21}$; c) postulado hermenéutico y de aplicación de las normas procesales penales, siendo fundamental para la conformación constitucional de estas normas.

a la verdad, empírica y lógicamente controlable, de sus motivaciones" (Ferrajoli, 1995, p. 22).

${ }^{20}$ Ya en la presentación de la obra, Prado (2019, p. 10), al afirmar que el asunto de la prueba penal está a la orden del día, advierte que "el desafío concreto radica no solo en entender el metalenguaje de la prueba penal, que define los términos de la interacción cuando se trata de persecución penal transnacional, y de ese modo evitar los daños causados por la importación inadecuada de modelos jurídicos, sino en situar el momento en el que se encuentra la controversia sobre las denominadas metodologías o dimensiones de la prueba en cada ordenamiento". Como la adopción o no del principio de la presunción de inocencia es el eje que estructura el modelo probatorio de cada país, puede obtenerse, cuando los modelos probatorios son comparados, un metanivel analítico sobre el principio de la presunción de inocencia, una lectura interparadigmática de este principio.

${ }^{21}$ En diverso sentido, para Nieva Fenoll (2013, p. 165), si, al final del proceso, aún persiste la duda sobre alguna cuestión relevante, no se debe partir, inmediatamente, hacia una solución radical, aplicándose el in dubio pro reo, dando la absolución al reo. Para él, "la mejor solución, por tanto, en caso de incertidumbre, no será la aplicación de ninguna regla radical, sino considerar probada la hipótesis que, pese a todo, cuente con mayores elementos que puedan fundamentarla científicamente tras la práctica de la prueba". 
Sobre "La cadena de custodia de la prueba en el proceso penal", de Geraldo Prado

De hecho, el principio de presunción de inocencia es una síntesis normativa constitucional del debido proceso penal y, también, la base axiológica para acceder a las correctas teorías del conocimiento sobre el proceso penal. Camina entre lo político, lo filosófico y lo jurídico a la hora de la formulación conceptual del moderno proceso penal equitativo. En medio de estas esferas del saber, parece situarse en un estado casi de metanivel procesal, metalenguaje procesal, fundamento, al mismo tiempo, externo e interno al proceso penal, de modo que esta imagen aparentemente paradójica (algo fuera, algo dentro del proceso) pronto se disuelve cuando se percibe al proceso penal como un curso dinámico de saberes heterogéneos.

Son estas impresiones que parecen surgir de la lectura de Prado (2019, p. 44) que afirma que "El papel que juega hoy la presunción de inocencia consiste, por tanto, en fundar un estado original de incertidumbre que marcará la persecución penal, desde la noticia del crimen hasta el momento inmediatamente anterior a la sentencia penal condenatoria"22. Prado (2019,

22 Prado (2019, p. 31) menciona que, "sobre el concepto construido a partir del consenso dogmático acerca del papel funcional de la presunción de inocencia", debe consultarse la perspectiva que aborda el valor normativista de la presunción de inocencia, que fue desarrollada por Carl- Friederich Stuckenberg con adhesión de Roxin, y abordada por Sánchez-Vera Gómez-Trelles, este último en relación al principio de la presunción de inocencia en el derecho procesal penal español. En este sentido, Sánchez-Vera Gómez- Trelles (2012, p. 16-17) realiza un análisis funcional de la presunción de inocencia a partir del Derecho Penal, cuando dice que "la presunción de inocencia sirve al Derecho penal (mal llamado material: solo hay uno, material y procesal) y, a la inversa, el Derecho penal sirve a la presunción de inocencia. Se tratará pues - así nuestro programa- de un análisis funcional de la presunción de inocencia: conforme a la esencial función que representa. [...]”. Sánchez-Vera Gómez-Trelles (2012, p. 30) entiende la presunción de inocencia como principio que fundamenta, teóricamente, tanto el Derecho Penal como el Derecho Procesal Penal, al considerar, frente a esta base principiológica en común, que no es tan necesaria esta subdivisión en Derecho Penal y Procesal Penal: “[...] el baluarte de la presunción de inocencia, pues no se trata de un principio más del proceso, es el proceso mismo; una directa prohibición de desautorizar el proceso. Por ello, todas las partes están asociadas: el proceso con la pena, y la pena, por ello, con la presunción de inocencia. Es el núcleo duro del Derecho penal. Podrán diferir estas piezas entre ellas, como si de una variación musical se tratase, pero todas nacen del mismo tema principal: la inocencia como sistema afortunadamente proclamado en el art. 24 de la Constitución". En la doctrina brasilera, Tavares (2019, p. 179), con base en el principio de la presunción de inocencia, propone un análisis dialéctico de los compartimentos del injusto penal (tipo y antijuridicidad), de modo que el tipo no debe ser interpretado como indicio de la antijuridicidad. El tipo es sólo una etapa 
p. 37), consciente del alcance epistemológico de la presunción de inocencia, rompe con la definición clásica de que el "proceso se inicia solamente cuando la acusación formal es admitida por el juez, al recibir la denuncia o querella”, para concebir la formación del proceso desde la noticia-crimen, con plena incidencia de la presunción de inocencia.

Para él (2019, p. 37), de este nuevo marco procesal ${ }^{23}$ se pueden "extraer diversas consecuencias tanto en el ámbito de la actividad probatoria como en la influencia sobre los estatutos jurídicos de los diversos sujetos que son personajes obligatorios en un contexto formado por elementos 'discursivos' y 'no discursivos"'.

En esta nueva dimensión formativa del proceso penal, Prado identifica otro fetiche que seduce la dogmática procesal. Poco se cuestiona sobre el libre convencimiento motivado, en el sentido de indagarse cómo se da el libre convencimiento motivado judicial en el proceso penal, si este cómo, en tanto camino judicial a ser recorrido para la determinación de los hechos en la sentencia, promueve una decisión penal de calidad, que se vale de filtros epistémicos en relación a la información probatoria aportada al proceso.

Según Prado (2019, p. 55), después de un período del proceso penal marcado por el sistema de la prueba tasada y por la íntima convicción, existe una sobreestimación dogmática del libre convencimiento motivado

metodológica que precede al análisis de la antijuridicidad, que solo podrá ser considerada existente cuando "se agoten todos los recursos en favor del predominio de la libertad". Y esto sucede, conforme lo dicho, porque en la verificación de estos compartimentos del injusto (tipo y antijuridicidad) debe incidir el principio de la presunción de inocencia (art. $5^{\circ}$, LVII, da CF/88).

${ }^{23}$ En dictamen sobre la posibilidad de los Conselhos Seccionais da Ordem dos Advogados do Brasil actuaran, mediante sus respectivos Presidentes, como asistentes en investigaciones criminales y procesos penales en que sean ofendidos los inscriptos en el cuadro de abogados de la OAB, Prado (2019, p. 341-342), al reforzar su posicionamiento jurídico sobre cuál sería el marco inicial del proceso penal brasilero, destaca la importancia de considerarlo desde la noticia-crimen, para que haya una mayor preservación de los derechos y garantías fundamentales de la persona investigada: "al ser el proceso penal un 'dispositivo' que a un tiempo contempla la 'búsqueda de la verdad' y la defensa de los derechos y garantías del imputado desde la noticia-crimen importa establecer límites a las prácticas, así como implica la redefinición de reglas jurídicas estableciendo, no solamente lo que las partes y demás sujetos procesales pueden o no hacer- desde la noticia crimen reitérese- pero, aun fijando objetivos públicos que convierten la mayoría de las acciones, particularmente la de carácter persecutorio, en actividades orientadas por el principio de la impersonalidad". 
Sobre "La cadena de custodia de la prueba en el proceso penal", de Geraldo Prado

puesta, en general, como la mejor forma para alcanzar una decisión justa. Prado (2019, p. 37) advierte sobre la necesidad de una nueva visión del libre convencimiento motivado, que debe resultar de una valoración racional de la prueba (explicitación de los razonamientos probatorios, recepción de aportes científicos, racionalidad epistemológica, respeto a la normatividad probatoria), precedida de una fase seria de admisibilidad probatoria. De lo contrario, puede haber un "aumento cuántico de los poderes judiciales" en la valoración de la prueba, tal como sucedió con la época autoritaria de la verdad real, que propició la ideología del Código de Procedimiento Penal de 1941, en el cual el juez era visto como un sujeto dotado de "superpoderes epistémicos" (Prado, 2019, p. 27).

La fetichización acrítica del libre convencimiento motivado en el ámbito jurídico contribuye a que el proceso penal no esté pensando en el propósito de garantizar la calidad epistemológica de la información y el material probatorio que se presentan en la fase investigativa, desde la noticia del crimen presentada a la autoridad policial o Ministerio Público. Más aún: contribuye a alimentar una creencia -no siempre ingenua- de que sería mejor admitir en el proceso el máximo de informaciones (aunque carezcan de fiabilidad), dejando a cargo del libre y prudente convencimiento judicial, al final del procedimiento, atribuir el correcto valor a cada elemento probatorio.

De esto no se puede concluir que Prado esté en contra del libre convencimiento motivado ${ }^{24}$. Su lectura de este modelo de toma de decisiones es que se muestra diferenciada, en un intento de conformarlo constitucionalmente. Los ojos epistemológicos de Prado se vuelven hacia el camino, la "carpintería de la sentencia penal"25, cuestionan cómo se realizó la deter-

${ }^{24}$ En realidad, el libre convencimiento motivado se somete al test de criticidad dogmática, para que se indague hasta qué punto este libre convencimiento motivado no se ve obstaculizado por creencias juiciosas.

25 Expresión utilizada por Perfecto Ibañez (2007, p. 120-123) para retratar la complejidad de la actividad judicial en la determinación de los hechos, abordando la quaestio facti (hechos empíricos) no es una materia inerte, lista y acabada cuando es introducida en el proceso. En realidad, es todo lo opuesto, porque, por regla, se refiere a hechos pasados, que serán introducidos, enunciativamente, en el proceso por medio de una actividad constructiva de las partes, debiendo el juez explicar, racionalmente, como alcanzó ciertas conclusiones. 
minación de los hechos. La epistemología es el puente que dará, al repeler el inquisitorio decisionismo psicologista, una "libertad condicionada" a la motivación de la decisión penal2 ${ }^{26}$.

Por su propia heterogeneidad, es importante pensar, como sugiere Prado, el dispositivo procesal a partir de un sistema de controles epistémicos que considere la formación del proceso desde la noticia del crimen, ejerciendo una constante vigilia sobre cuestiones de preservación y garantía de la integridad de la prueba en todo el curso del proceso penal.

\section{Dispositivos probatorios y sistema de controles epistémicos}

La epistemología jurídica puede alertar sobre cambios en relación a la práctica procesal de determinados medios de prueba, como la prueba testimonial y el reconocimiento de personas, que han sido estudiados por la psicología cognitiva, comprometida en el análisis de las susceptibilidades de la memoria humana en los procesos de codificación, almacenamiento y recuperación de informaciones ${ }^{27}$. También puede indicar la necesidad de modificación de una etapa procesal, con el objetivo de que el contexto

${ }^{26}$ Sin intención de minimizar el potencial de la racionalidad epistemológica para el justo acierto de la decisión penal, Dei Vecchi $(2019$, p. 46) cuestiona la capacidad que la epistemología tendría para garantizar, con exactitud, el acierto de la justificación de la decisión judicial, de modo que debe ser visto, con crítica equilibrada, lo que convencionalmente se denominó en el proceso penal español de "la sana crítica racional": "Por su parte, la epistemología tampoco proporciona un criterio categórico que nos permita decir cuándo una justificación es epistémicamente suficiente. En el mejor de los casos, lo que la epistemología pone a nuestro alcance es algo así como un criterio de resignación según el cual la mejor hipótesis ha de tenerse por la verdadera (sea lo que fuere que la hace mejor), aun si esa hipótesis se presenta, aisladamente, como improbable."

${ }^{27}$ En esta área de la psicología, los hallazgos empíricos recomiendan que la preguntas dirigidas a los testigos sean abiertas (“¿qué sabe el testigo sobre el hecho?), evitándose sugestiones que comprometan la calidad de la información a ser obtenida. En cuanto al reconocimiento de personas, estudios científicos muestran que la iluminación de la escena del crimen, uso de arma de fuego, estrés provocado por el delito, momento de reconocimiento son diversas variables que interfieren en la fiabilidad probatoria del reconocimiento de personas. En este sentido: Cecconello, W. W., de Ávila, G. N., y Stein, L. M. (2018); Cecconello, W. W., y Stein, L. M. (2020). 
Sobre "La cadena de custodia de la prueba en el proceso penal", de Geraldo Prado

probatorio del proceso sea amplio, propenso a la adquisición de pruebas relevantes y, sobretodo, fiables.

De hecho, la epistemología, desde un punto de vista probatorio, tiende a preocuparse por la amplitud, calidad e intensidad de la cognoscibilidad de las cuestiones de hecho que fundamentarán la decisión judicial. Para este objetivo, la epistemología tiene la capacidad de dirigir su propia producción normativa sobre la prueba penal, sugerir nuevos comportamientos procesales $y$, en definitiva, promover la transformación paradigmática de una determinada cultura procesal en relación al derecho probatorio. Por estar atravesada por contenidos científicos, filosóficos, lógicos, teórico-lingüísticos, la epistemología es una fuerza incansable de pensamiento que se ofrece al mundo que, para el análisis sobre la cadena de custodia, es el mundo del proceso penal.

Con esto, el proceso penal no se convierte en rehén de la racionalidad epistemológica, porque el proceso integra la palpitante fenomenología social. Simplemente significa que el proceso penal no puede transformarse en un desperdicio de la razón científica, de la observación empírica guiada por fuertes razonamientos inferenciales ${ }^{28}$.

Como se anunció anteriormente, además de controlar epistémicamente un determinado medio de prueba, es posible concebir una arquitectura procesal general, adecuada para estructurar, en la fluidez heterogénea de los elementos procesales (proceso como dispositivo), un sistema de controles epistémicos. Sistema político y sistema jurídico, en las interrelaciones de la administración de la justicia penal, pueden concebir una etapa procesal en la cual el control epistémico se intensificaría, sin dejar de ser retomado en otros momentos del proceso penal.

${ }^{28}$ De acuerdo con Matida y Herdy (2019, p. 212): "la inferencia probatoria es el razonamiento utilizado por el tomador de la decisión judicial para justificar la determinación de una cuestión de hecho en el tribunal. Una inferencia (probatoria o no) está formada por un conjunto de proposiciones, llamadas premisas, que son ofrecidas como razones para dar sustento a una conclusión. En el caso de las inferencias probatorias, las proposiciones que dan sustento a la conclusión se refieren a las informaciones probatorias disponibles en el proceso; por otro lado, la conclusión constituye la hipótesis fáctica a ser asumida como premisa en la inferencia judicial mayor que justificará la decisión final”. 
En otras palabras, el procedimiento penal, desde su concepción normativa, puede ser pensado y reestructurado para atender la necesidad de justificación epistemológica del proceso penal y, en consecuencia, de los respectivos controles epistémicos sobre la prueba penal. El principio de la presunción de inocencia, como base (política, normativa, axiológica) estructurante del proceso penal, requiere que los aportes epistemológicos subsidien el conocimiento del caso penal, respetándose siempre la fundamentalidad constitucional del proceso penal, que repele cualquier amenaza de retroceso con respecto a derechos y garantías fundamentales.

De manera ilustrativa, piénsese que el vocablo standart no debe usarse solamente para indicar el grado de suficiencia probatoria que determinado ordenamiento jurídico considera para condenar a una persona. Incluso desde una perspectiva garantista, los diferentes momentos probatorios del proceso penal requieren la verificación de standards informacionales (conocimiento potencialmente esclarecedor) que justifiquen la existencia y continuidad de una etapa procesal. ¿Tendrá sentido continuar una investigación evidentemente sin potencial de captar elementos informativos? ¿Podrá presentarse una denuncia a partir de una investigación que recolectó elementos informativos de baja fiabilidad? La idea de suficiencia probatoria debe acompañar el proceso penal de punta a punta, respetando la densidad y peculiaridad de cada etapa procesal. De este modo, al final, se vuelve probable que la decisión penal sea procesal y materialmente justa, alimentada por una noción de verdad como indicador epistémico de la realización del proceso.

La decisión penal no puede ser un collage sofista de retazos probatorios. Esperar que la seriedad metodológica, que debe guiar la dinámica probatoria, esté reservada a la valoración judicial puede comprometer la propia confiabilidad del proceso penal. El compromiso epistemológico del proceso penal debe producirse desde la investigación hasta el último suspiro procesal que precede a sentencia condenatoria firme.

Prado (2019, p. 66-68), atento a esta transversalidad epistemológica del proceso penal, propone que, con la reforma procesal penal brasilera del año 2008, que modificó los artículos 155, 157, 395, 396 y 397 del CPP, el procedimiento penal pasó a ser trifásico. Además de la investigación penal y la instrucción probatoria, entre estas dos etapas se incluye la etapa de admi- 
Sobre "La cadena de custodia de la prueba en el proceso penal", de Geraldo Prado

sibilidad del auto de procesamiento. Según Prado, esta etapa intermedia es de suma importancia para que exista un filtro judicial frente a acusaciones imprudentes, superficiales, irresponsables, sin sustento probatorio o referenciadas por fuentes ilícitas de prueba.

Para Prado (p. 69-72), el filtrado procesal de la acusación es una actividad propia del sistema de controles epistémicos, marcada, esencialmente, por el control judicial de la fiabilidad de los elementos informativos y pruebas producidos para sustentar la acusación y por el Discovery, que sería verificar si la defensa, ya en fase de investigación, tuvo acceso a las fuentes de prueba, principalmente, pero no solo, a aquellas que pueden beneficiarla, desestimando la existencia del proceso. De esta forma, en esta etapa procesal, la defensa podrá comprobar y cuestionar, inclusive indicando la necesidad de producción de pruebas de segundo orden (prueba sobre prueba), la integridad de las fuentes de prueba presentadas por la fiscalía al momento de realizar la imputación de un delito.

Cabe señalar que Prado no solo establece un nuevo marco para la existencia del proceso penal propiamente dicho, que comienza con la noticia del crimen, sino que también le da un nuevo color, más democrático, a la garantía constitucional de defensa amplia, ya que la define como la posibilidad constante y dinámica de la defensa para rastrear y verificar la integridad de las fuentes de prueba que justifican el proceso penal.

Y, si bien el libro de Prado había sido publicado incluso antes de la aprobación de la ley que introdujo en el Código Procesal Penal una norma específica sobre el tema (arts. 158A-158F), lo cierto es que el autor ya defendía, incluso antes del cambio legislativo, que la cadena de custodia era un elemento necesario y fundamental para la efectivización de diversos derechos fundamentales y un corolario lógico del propio principio de legalidad (2019, p. 97), ligado precisamente a estos objetivos: permitir un contradictorio con la debida densidad y garantizar el ejercicio del derecho de defensa en toda su amplitud. Literalmente, en ese momento, el autor ya señalaba que "si bien el derecho brasilero no dispone de una regla específica sobre la cadena de custodia de las pruebas la consecuencia de su violación debe ser removida de la constatación de que el contradictorio, como condición de validez constitucional del acto procesal, igualmente fue vulnerado, volviendo ilícitas las restantes pruebas" (2019, p. 128). 
Por otro lado, hay también una justificación para la observación empírica, Prado (2019, p. 68) menciona que un sistema eficiente de controles epistémicos es indispensable, porque "se popularizó recurrir, en el ámbito de la investigación, a métodos ocultos de investigación (intercepción de comunicaciones, vigilancia continua y violación de secretos)" y, en este contexto de investigaciones abusivas, "la totalidad de los elementos de información que sustentan las acusaciones se encuentran basados en elementos obtenidos de esta manera".

Como lenguaje procesal, en lo que respecta a la cadena de custodia, el control epistémico recaería sobre toda la investigación penal, reforzando el control de legalidad y fundamentalidad constitucional que se espera de la fase intermedia del proceso penal. Por lo tanto, se abre otro marco de concepción teórico- práctico: pensar la investigación penal a través de un razonamiento epistemológicamente orientado ${ }^{29}$.

En este contexto, corresponderá al juez de garantías, incorporado al CPP brasilero en virtud de la Ley $n^{\circ} 13.964 / 2019$, realizar el control epistémico de la investigación, "siendo responsable del control de legalidad de la investigación penal y de salvaguardar los derechos individuales", correspondiéndole decidir el recibimiento de la denuncia o querella. Debido a la "microrreforma" procesal penal de 2019, no se enviarán expedientes de investigación al juez de instrucción y juzgamiento, salvo los documentos relativos a las pruebas irrepetibles, medidas de obtención de pruebas o de anticipación de pruebas, que deberán ser enviados en expedientes separados (art. 3-B, inciso XIV, $\$ 3^{\circ}$, del CPP).

En este paso, es perfectamente posible decir que estas modificaciones legislativas, ocurridas poco tiempo después de la publicación de la obra de

29 Aguilera García (2020, p. 17-42) destaca que la etapa de investigación debe recibir una adecuada atención epistemológica, centrada en el tipo de razonamiento probatoria (abductivo) que suele prevalecer en esta etapa del procedimiento penal. Utilizando las explicaciones de Giovanni Tuzet sobre el razonamiento abductivo, el mencionado autor advierte que las preocupaciones epistemológicas sobre el derecho probatorio tienden a prevalecer sobre la etapa de admisibilidad de los medios probatorios y la justificación de la decisión judicial, olvidándose de la investigación. Para él, se debe corregir esta incidencia asimétrica y desproporcional de la epistemología en el procedimiento penal, que tiende a omitir la investigación preliminar y, con esto, no reduce, adecuadamente, la ocurrencia y la repetición de errores judiciales en el proceso penal. 
Sobre "La cadena de custodia de la prueba en el proceso penal", de Geraldo Prado

Prado, atienden muchos de sus reclamos, en la medida en que favorecen la preservación de la calidad epistemológica del proceso penal para quien va a juzgar la cuestión penal, evitándose, al máximo, que se tenga, en la instrucción y en el juzgamiento en sí, contacto judicial con el material que fue producido en la investigación, como regla de bajísimo contradictorio. Y lo contradictorio es, por excelencia, una garantía epistemológica.

Sin embargo, es necesario dejar constancia que los artículos recientemente introducidos y que tratan del juez de garantías (arts. 3-A - 3-F del $\mathrm{CPP}$ ) tuvieron la validez suspendida por decisión dictada como medida cautelar de acción directa de inconstitucionalidad en el Supremo Tribunal Federal (Adis n. 6298, 6.299. 6.300 y 6.305). El establecimiento de una madura fase intermedia en el proceso penal brasilero, realmente orientada a analizar la fiabilidad de las fuentes de prueba recabadas en la investigación y la viabilidad de instaurar la etapa judicial instructoria, aún es algo que aparentemente está lejos de concretarse.

Cabe señalar también que, en países de América Latina, que han experimentado reformas procesales globales de sus CPP (Costa Rica, Panamá, Perú, Guatemala), en los cuales la fase intermedia del proceso penal se encuentra bien delimitada por la ley, el día a día del sistema de justicia penal ha revelado una verdadera distorsión y debilitamiento de esta etapa procesal.

Mauricio Duce (2020, p. 103-132) relata, con base en datos empíricos, que en Chile, la etapa de preparación del juicio oral (etapa intermedia), que se desarrolla en una audiencia preliminar conducida por el juez de garantías $^{30}$, no ha cumplido, satisfactoriamente, con una de sus principales funcionalidades, que sería el control de admisibilidad previa de la prueba que ingresará en el proceso. Los reconocimientos de personas, las pruebas testimoniales y periciales han sido generalmente admitidas, sin una discusión sólida sobre su pertinencia para conformar la fase del juicio oral, sobre

${ }^{30}$ Gallardo (2020, p. 9) advierte que "en efecto, la concreción del principio acusatorio exige comprender una cuestión muchas veces ignorada, a saber: la diferenciación estructural y epistémica entre la fase de investigación y la fase de juzgamiento (en modelos como el Chileno el proceso en rigor contempla tres fases: la investigativa, la intermedia en la cual se controla la legalidad de las pruebas y la del juicio oral propiamente, interviniendo el juez de garantía en las dos primeras)". 
todo porque, en la práctica, las respectivas audiencias de preparación del juicio oral han tenido una duración muy corta ${ }^{31}$.

Continuando con su análisis, Prado (2019, p. 72), a partir de la premisa de que la elección de un sistema de controles epistémicos, en condición de preservación de las garantías del imputado, es un fundamento ético del proceso penal, analiza algunos aspectos del Discovery, destacando la importancia de aplicar este instituto, de caracterización norteamericana, al proceso penal brasilero.

Para el citado autor (2019, p. 74-75), la historicidad inquisitoria del proceso penal brasilero, resistente a la luz democrática que emana de la Constitución, indica una asimétrica dinámica de poderes institucionales en el proceso penal, que puede resultar en la llamada "aglomeración cuántica del poder" de la policía, del Ministerio Público o del Poder Judicial. La división estática de las funciones procesales penales no es suficiente para garantizar el sistema acusatorio procesal penal. En la práctica, esta división puede ser corrompida por una de las agencias formales de control de la criminalidad (Policía, Ministerio Público o Poder Judicial), en la medida en que una de estas agencias se comporte como una institución de "superpoderes", lo que silencia a las otras instituciones, usurpándolas en sus funciones, momento en el cual se reverbera el autoritarismo procesal ${ }^{32}$.

Según Prado (2019, p. 78-86), el Discovery, al permitir a la defensa, desde la etapa investigativa, rastrear las fuentes de prueba disponibles,

${ }^{31}$ Conforme destaca Duce (2020, p. 114-115), “esta práctica indicaría que el sistema está operando con unos ciertos niveles de automatismo en la admisión de prueba testimonial ya que esas decisiones se adoptan con muy poca información sobre lo que se espera aporten los testigos y, por lo mismo, se hace imposible sostener debates en serio sobre temas tan básicos como su pertinencia."

32 Sobre la relación entre los estatutos estáticos y dinámicos de los sujetos procesales en el proceso penal, Prado realizó un amplio análisis en su libro Sistema Acusatório. A conformidade constitucional das leis processuais penais (2006), que es otra gran referencia en la literatura procesal brasileira. En la mencionada obra, la construcción teórica del referido autor señala que, en la práctica, cuando uno de los sujetos pasa a ejercer funciones procesales que le cabría al otro sujeto, se distorsiona la perspectiva de conformidad constitucional del sistema acusatorio. Es lo que sucede cuando el juez se coloca en la condición de investigador o se predispone a sustituir la actividad de la acusación que le corresponde al Ministerio Público. Esta distorisión del sistema acusatorio caracteriza una de las posibles aglomeraciones cuánticas de poder en el proceso penal, ya que tanto la autoridad policial 
Sobre "La cadena de custodia de la prueba en el proceso penal", de Geraldo Prado

permite que el equilibrio acusatorio en el proceso penal sea una realidad a ser experimentada cuanto antes, sin necesidad de esperar la etapa judicial instructoria. La defensa se vuelve muy activa. Deja de ser mera espectadora de los elementos de información presentados por la acusación. Comienza a provocar que la autoridad investigadora verifique otras hipótesis, que indiquen, por ejemplo, la ausencia de elementos de información sobre la autoría o materialidad delictiva. O, si es factible, la propia defensa, luego de acceder a las fuentes de prueba, investiga y proyecta sus hipótesis sobre el caso, presentándolas al juicio responsable de la fase intermedia del proceso penal (investigación defensiva).

En este sentido, el Discovery se muestra como un instituto seriamente comprometido con la equiparación de los poderes procesales desarrollados en las prácticas probatorias, con un fuerte potencial para evitar la indeseada acumulación cuántica de poderes descripta por Prado ${ }^{33}$. Justificada por la necesidad de una validación práctica del principio del debido proceso penal, el instituto de Discovery, según Prado (2019, p. 85), al aplicado en el proceso penal brasilero, garantizaría la "prohibición de sorpresa (unfair surprise)", imponiendo también a la acusación el deber de "preservar los elementos de información obtenidos y poniéndolos a disposición de la defensa siempre que fuera necesario".

y el Ministerio Público también pueden alejarse de sus funciones constitucionales, con prácticas incompatibles con la propuesta de un justo y equitativo proceso penal.

${ }^{33}$ En un texto en el cual realizó un análisis crítico sobre el proceso penal después de 25 años de vigencia de la Constitución Brasilera, Prado (2013, p. 562) ya había advertido que la realidad "desafía un nuevo esfuerzo interpretativo de la doctrina procesal penal, apunta al fenómeno de la aglomeración cuántica de poder en las manos de los sujetos procesales que reúnen tareas preventivas que, con cierta frecuencia, caen en abusos, en un creciente derecho penal y procesal penal preventivo. Para esto, se presenta indispensable ir más allá de la etapa estrictamente técnico-jurídica del proceso penal como condición de superación de la mentalidad inquisitoria". En el texto mencionado, Prado también informa que la expresión aglomeración cuántica de poder fue usada por Bernd Schünemann para referirse al establecimiento de una excesiva red de persecución penal en las llamadas "Leyes de Lucha" contra la criminalidad en Alemania. En La cadena de custodia en el proceso penal, Prado (2019, p. 73-74) destaca que, además de Bernd Schünemann, el jurista alemán Claus Roxin también hizo uso de la expresión acumulación de poderes, vinculada a modelos de Estados autoritarios. 
Prado (2019, p. 85) enfatiza que "el filtro procesal contra las pruebas ilícitas depende del rastreo de las pruebas a las fuentes de prueba (elementos de información) y la ilicitud probatoria, directa o por derivación, es más fácilmente detectable siguiendo este rastro producido entre las fuentes de prueba y los elementos (medios) probatorios propiamente dichos". Por lo tanto, discovery es un importante instrumento de control epistémico en el proceso penal.

La epistemología jurídica aplicada al proceso penal indica la necesidad de custodiar las fuentes de prueba, de adoptar medidas para su preservación, para que la integridad probatoria del proceso penal no sea deshecha por manos que, con conjeturas investigativas, acusativas y, en la peor de las hipótesis, decisionistas, anhelan una necesidad irreprimible de castigar (conviction at any cost - Zoukis, 2014).

De hecho, se debe prestar especial atención procesal a la fiabilidad probatoria, al momento y forma procesal adecuada para analizarla, lo que requiere un gran compromiso académico y de los profesionales del sistema de justicia con respecto a la cultura probatoria en el proceso penal brasilero, mal acostumbrado a los excesivos poderes instructorios otorgados al juez.

Los sistemas de control epistémicos son sumamente importantes para garantizar la fiabilidad probatoria y evitar decisiones judiciales que, aunque dotadas de cierta cognoscibilidad para la determinación de los hechos, se presentan epistemológicamente laxas, con gigantescos saltos inferenciales, equiparándose al decisionismo inquisitorial.

\section{Fiabilidad probatoria, ruptura de la cadena de custodia e inadmisibilidad de la prueba.}

Luego de establecer nuevas perspectivas sobre el debido proceso penal, destacando la funcionalidad epistémica que la verdad ejerce en el proceso, visto como ambiente de confluencia de elementos discursivos y no discursivos, Prado se dedica a examinar el árido tema de la fiabilidad probatoria, con reflexiones que profundizan la exigencia de que los sistemas de controles epistémicos deben regir la dinámica probatorio del proceso penal.

De hecho, entre los principales aditamentos que el libro de 2019 mereció en relación al de 2014, cabe destacar que la obra más reciente, centrada 
Sobre "La cadena de custodia de la prueba en el proceso penal", de Geraldo Prado

en la cadena de custodia de la prueba, recibió una mayor atención en relación al tema de la fiabilidad probatoria. La cuestión - hasta entonces poco tratada en el ámbito de la doctrina procesal penal brasilera - fue muy bien desarrollada por Prado en los años que siguieron a la publicación del primer libro, especialmente después de que este tema fuera objeto de un análisis cuidadoso en otro dictamen del autor (2015), para ser agregado al expediente del proceso penal que tramitaba en la primera instancia de la justicia de San Pablo, donde se debatía el tema de la fiabilidad de la prueba y de la ruptura de la cadena de custodia, en el contexto de la imputación del delito de competencia desleal.

Con respecto al tema, cabe señalar que Prado $(2019$, p. 87) parte de la idea de que la cadena de custodia de las pruebas integra un sistema más amplio, que comprende diversos dispositivos o herramientas dedicadas al ejercicio del control epistémico que debe realizarse en toda la recopilación de informaciones que ingresa al proceso y que deberá ser oportunamente valorada por el juez. Y este control epistémico se revela imprescindible precisamente por el interés que existe por evitar que sean valorados ( $\mathrm{y}$, por tanto, puedan influir en la toma de decisiones sobre los hechos) elementos de prueba que no satisfagan los requisitos de licitud, integridad y confiabilidad. Todo esto, según la lección de Prado (2019, p. 87), está íntimamente ligado a la idea de debido proceso y de proceso justo y equitativo.

En esta línea, Prado (2015b, p. 34) sostiene que "el cuidado que involucra el tema de la formación de la prueba tiene en cuenta cuestiones de orden práctico como, por ejemplo, la manipulación indebida del elemento probatorio con el propósito de incriminar o eximir a alguien responsabilidad y, también cuestiona, a nivel teórico, las condiciones concretas para un mejor conocimiento judicial. En otras palabras, se trata de perseguir la mejor calidad de la decisión judicial y reducir al máximo los riesgos de criminalización indebida".

El autor llama la atención sobre una distinción fundamental - también hasta entonces poco debatida en la doctrina brasilera - entre el momento de la actividad probatoria reservado a la admisibilidad y el reservado a la valoración de la prueba, aclarando que se trata de cosas distintas (Prado, 2019 , p. 87). La advertencia, que podría no ser tan necesaria para los lectores más familiarizados con las discusiones trabadas en el derecho com- 
parado, fue un aspecto crucial para que los lectores brasileros entendieran un punto central de la tesis, desarrollada a partir de ahí, en el sentido de que la ruptura de la cadena de custodia, por comprometer la fiabilidad probatoria, debería tener como consecuencia la inadmisibilidad de la prueba, con el mismo tratamiento que el ordenamiento jurídico brasilero le da a la prueba ilícita.

Al respecto, Prado aclaró que "preguntar por la fiabilidad de una prueba no es lo mismo que indagar por su 'peso', es decir, por su valor para la formación de la convicción del juez" (2019, p. 87). Y continúa el autor: "Son cosas distintas, por lo tanto, saber si un determinado elemento probatorio está en condiciones de ser evaluado, es decir, si el elemento probatorio puede ser objeto de evaluación, y en caso de ser 'evaluable', saber qué valor le atribuye el juez" (Prado, 2019, p. 88). A continuación, Prado dialoga con la doctrina de Ferrer Beltrán (2007) y Gascón Abellán (2013), en particular, para establecer las premisas que lo conducen a la conclusión sobre la importancia que tiene el filtro de admisibilidad, como herramienta de control epistémico, impidiendo el ingreso de pruebas cuya fiabilidad estuviera comprometida, o incluso de aquellas en que la fiabilidad no se puede certificar. En este escenario, la evaluación de la fiabilidad probatoria tendría relación directa con la valoración de la confianza que se pueda depositar sobre determinado elemento de prueba, lo que es una condición determinante, naturalmente, para que este dato pueda ser tomado y valorado por el juez.

Según su posición, solamente las pruebas fiables - esto es, pruebas cuya autenticidad e integridad estuvieran aseguradas y puedan ser verificadas (dado que una de las consecuencias de la llamada dimensión epistémica del principio del contradictorio residiría en el derecho de la parte contraria a poder rastrear las fuentes y evaluar la fiabilidad de las pruebas presentadas por la parte adversa, incluida la proposición de pruebas sobre las pruebas ${ }^{34}$ ) - pueden ser valoradas, debiendo la etapa de admisibilidad actuar como

\footnotetext{
${ }^{34}$ Según Gascón Inchausti (1999, p. 11), cuando se habla de “'prueba sobre la prueba’ se está refiriendo a ciertas pruebas que se practican en el proceso con la finalidad de desvirtuar o de corroborar la eficacia probatoria de otras". En síntesis, y de acuerdo con Ferrer Beltrán (2007, p. 87), se trata de pruebas que sirven para el control "sobre la fiabilidad de las pruebas existentes, que la confirme o la impugne. Se trata de pruebas que no versan directa
} 
Sobre "La cadena de custodia de la prueba en el proceso penal", de Geraldo Prado

una barrera para contener el riesgo de que pruebas no fiables ingresen al proceso y sean consideradas en el momento de la valoración.

En Brasil, ya se había manifestado en este sentido Ada Pellegrini Grinover (2013, p. 254), para quien, "en el caso de producción de una prueba técnica sin la mínima observancia de la técnica o método adecuado, la cuestión no será resuelta en el plano de la valoración de la prueba, sino que el problema está relacionado con su admisión: la prueba técnica será inadmisible”. De manera aún más detallada, la profesora de la Facultad de Derecho de la Universidad de San Pablo (2013, p. 254) aclaró que "la cuestión no debe resolverse admitiéndose la prueba y remitiendo el problema al momento de la valoración. El sistema del libre convencimiento o libre apreciación de la prueba, en contraposición al sistema de la prueba legal, se refiere al método de valoración de la prueba, liberando al juez de las ataduras previas y abstractas, realizadas por el legislador, en el sistema de la prueba legal. La valoración de la prueba es una etapa lógica y cronológicamente posterior a la admisión y a la producción de la prueba".

¿Y por qué razón sería peligroso permitir la valoración de pruebas con déficit de fiabilidad? Es que, según Prado - y de acuerdo con las enseñanzas de Gascón Abellán (refiriéndose especialmente a la prueba científica) existiría en estos casos un riesgo inherente de sobrevaloración probatoria (overwheighting), tanto en la dimensión epistémica como en la semántica ${ }^{35}$. Por lo tanto, excluir la admisibilidad de las pruebas carentes de fiabilidad, como forma de prohibir su valoración (Miranda Estrampes, 2004, p. 101102), consiste, pues, en la forma más segura de impedir la sobrevaloración, con todas las consecuencias indeseables que esto puede traer para la toma de decisión sobre los hechos en el proceso.

ni indirectamente sobre los hechos del caso, sino sobre otras pruebas, y son esenciales en muchos casos para una correcta valoración individual de la prueba, en aras a determinar el grado de fiabilidad que ofrece".

${ }^{35}$ En la lección de la Profesora Catedrática de la Universidad de Castilla la Mancha (2013, p. 182), "La sobrevaloración de la prueba científica se da en una doble vía. Por un lado, sus resultados se aceptan como infalibles. Pero por otro, y sobre todo, se considera que esos resultados dicen cosas distintas de las que en realidad dicen. La primera es, pues, una sobrevaloración epistemológica. La segunda es - por así decirlo - una sobrevaloración semántica”. 
Explica Prado (2019, p. 95), con una cita expresa de la doctrina de Juan Carlos Urazán Bautista (2005), "la autenticidad del elemento [probatorio] constituye seguridad para la administración de justicia”, fundamentándose la exigencia de la preservación de la cadena de custodia en el "principio universal de 'autenticidad de la prueba', definido como 'ley de mismidad, esto es, el principio por el cual se determina que 'el «mismo» que se encontró en la escena [del crimen] es "el «mismo» que se está utilizando para tomar la decisión judicial"'.

De hecho, el razonamiento desarrollado por el autor va en la dirección de permitir la valoración de un elemento de prueba que no se sabe si es el mismo que está relacionado con el delito o incluso de un elemento que haya sufrido algún tipo de deterioro o contaminación (aunque involuntariamente) sería una elección demasiado arriesgada, dado el peligro de que este elemento sea sobrevalorado o incluso en función de las dificultades de control en cuanto al valor probatorio conferido por el juez a aquel dato.

Para ejemplificar, cabría preguntarse: ¿Qué valor podría atribuirse, por hipótesis, a una prueba pericial - metodológicamente, muy bien realizada de un arma que no se sabe si es la misma que fuera encontrada en la escena del crimen? ¿Qué valor probatorio se le podría conferir al examen de una muestra de ADN, por grande que sea la likelihood ratio que este tipo de prueba puede tener, cuando existe duda sobre la posibilidad de intercambio o contaminación de la muestra examinada? De hecho, en todos estos ejemplos habría un enorme riesgo de que, por deferencia al perito (Vázquez, 2015 , p. 81) o incluso por la propia aura de infalibilidad que conduce a una cierta beatificación de este tipo de pruebas (Gascón Abellán, 2013, p. 182), el resultado de la prueba sea altamente considerado en el razonamiento probatorio desarrollado por el juez, aunque esta información pueda conducir a un juicio totalmente erróneo sobre los hechos.

Por lo tanto, sería aún más recomendable que no se permitiese la entrada en el proceso de este elemento de prueba sobre el cual recaigan problemas de fiabilidad, obstando que llegue a la etapa de valoración. Por tanto, los jueces deberían entonces cumplir, a raíz de lo que enseñan Gascón Abellán (2013, p. 191) y Michele Taruffo (2013, p. 204), el rol de gatekeeper (expresión que fue acuñada por el Justice Blackmun, en el momento del juicio del caso Daubert v. Merrell Dow, en 1993, por la Suprema Corte 
Sobre "La cadena de custodia de la prueba en el proceso penal", de Geraldo Prado

de los Estados Unidos), procediendo a un riguroso control de admisibilidad de las pruebas, para no permitir el ingreso al proceso de pruebas que no cuenten con la necesaria certificación de su fiabilidad, como sucede con las pruebas producidas con ruptura de la cadena de custodia.

Todo ello, evidentemente, atraviesa un cambio en cuanto al comportamiento normalmente adoptado en relación a las pruebas aportadas a los procesos judiciales (muchas veces, partiendo de una credulidad exagerada), en el sentido de asumir una postura de cierto escepticismo epistémico. Este escepticismo implica la adopción de actitudes guiadas por lo que Prado (2019, p. 95), con apoyo en las lecciones de Baytelmann y Duce (2004, p. 135), denomina de lógica de la desconfianza, sintetizada por los citados profesores chilenos con la siguiente afirmación: "Nadie tiene que creer que esto es lo que la parte dijo que es, simplemente porque lo afirma". Es decir: toda y cada una de las alegaciones sobre un hecho jurídicamente relevante debe ser corroboradas con pruebas que atestigüen su origen y fidelidad.

Por lo tanto, debe concluirse que no hay lugar, en el proceso judicial, para conceder a ninguna de las partes confianzas preconcebidas (Baytelman \& Duce, 2004, p. 135). Esto es precisamente lo que explican Baytelman y Duce (2004, p. 135): "En principio, en el juicio oral no hay confianzas preconcebidas, de manera que, si el fiscal pretende que este cuchillo ensangrentado que trae al juicio es el arma hallada en el sitio del suceso, tiene que presentar información sobre eso más allá de su propia palabra".

Los profesores chilenos (2004, p. 135-136) también señalan que la lógica de la desconfianza se justifica por dos razones principales: i) estos elementos probatorios se producen sin inmediación, es decir, el juez no estaba presente en el momento de la formación de la prueba ; y ii) ninguna de estas pruebas fue sometida al contradictorio al momento de su producción, por lo que, en estos casos, la contradicción operará no solo en relación al contenido de la prueba (cuando entra en el proceso) sino también en lo que concierne a su autenticidad, a partir de la comprobación de la cadena de custodia.

En palabras de Prado (2019, p. 97), por lo tanto, "los principios de la 'mismidad' y de 'desconfianza' son fundamentales para garantizar el juicio a través de la reducción de los riesgos de error judicial, consistente en el fundamento lógico y epistemológico de la 'cadena custodia de las pruebas'. Y, aún con apoyo en la doctrina de Baytelmann y Duce, Prado (2015a, p. 
61) agrega que "la principal consecuencia de la lógica de la desconfianza consiste ' en la exigencia de que objetos y documentos deban en general ser 'acreditados', esto es, que sean sometidos a un procedimiento que demuestre que tales objetos son lo que la parte alega ser".

Concluye Prado (2019, p. 124) que la imposibilidad de acreditación de estos elementos probatorios, dada la imposibilidad de atribuirles suficiente fiabilidad, deberá reservarles el mismo tratamiento que para las pruebas ilícitas, con la consecuente inadmisibilidad de la prueba. En su visión, por lo tanto, no sería adecuado y suficiente abordar la cuestión de la ruptura de la cadena de custodia mediante el régimen propio de las nulidades procesales, siendo necesario ir más allá, para situar la cuestión en el terreno de la ilicitud probatoria. Es que, para el autor (2019, p. 125-126), "las nulidades constituyen técnicas destructivas con efectos de mucha menor intensidad que aquellas que resultan de la inadmisibilidad jurídica de un determinado acto, que es el régimen jurídico de las pruebas ilícitas según nuestra Constitución".

Como señala Prado (2019, p. 126-127), "la posibilidad de que los actos nulos sean subsanados debilita la función normativa de protección que es la esencia del proceso penal", por lo que "en el ámbito de las prohibiciones de la prueba, marcadas por valor superior de la dignidad de la persona humana, la tendencia de los ordenamientos jurídicos es la de no conformarse con el régimen de las nulidades". Así, según el autor (2019, p. 126), los casos de falta de fiabilidad por ruptura de la cadena de custodia reclamarían tratamiento "más estricto de la 'admisibilidad / inadmisibilidad', que prohíbe la valoración de la prueba no fiable y exige su exclusión del proceso, tal como se dispuso expresamente en la reforma procesal de 2008, que modificó el art. 157 del CPP brasilero.

Lo que se desprende de la posición de Prado (2019, p. 128), en este punto, es que la ruptura de la cadena de custodia acarrea la imposibilidad de ejercicio efectivo del contradictorio (notablemente en el plano de uno de los aspectos de su dimensión epistémica, que comprende el derecho de rastrear las fuentes de prueba y proponer pruebas sobre pruebas, que impugnen la fiabilidad de las pruebas ofrecidas por la otra parte ${ }^{36}$ ), que cuatro tipos de controles probatorios: 1) un control sobre la correcta aplicación de las reglas 
Sobre "La cadena de custodia de la prueba en el proceso penal", de Geraldo Prado

actúa como "condición de validez constitucional del acto" que da lugar a la ilicitud del elemento probatorio en cuestión.

Además de todos estos aspectos que ya justificarían, a juicio del autor, que la ruptura de la cadena de custodia reclamara la misma disciplina jurídica que la ilicitud probatoria, Prado destaca un punto adicional. Apoyado principalmente en la lección de Antonio Magalhães Gomes Filho (2003, p. 93-95), el autor llama la atención sobre el hecho de que la gran diferencia entre abordar la cuestión en el campo de la admisibilidad o de la valoración residirá en el momento en que llevará a cabo el pronunciamiento judicial con respecto a la cuestión, con todas las consecuencias procesales que de ello se deriven. Como bien dice Prado (2019, p. 127), "la admisibilidad requiere un examen previo, anticipado, de la cuestión porque mientras el acto produce sus efectos perdura la lesión de los derechos fundamentales de alguien".

El profesor carioca tiene toda la razón, pues si la cuestión atinente a la falta de fiabilidad de la prueba (por la ruptura de la cadena de custodia) fuese resuelta en el momento de la valoración, esto significa, en la práctica, que solo habrá un pronunciamiento judicial al respecto al final del todo el procedimiento, en el momento de la sentencia. Si, por el contrario, la cuestión fuese examinada en términos de admisibilidad, deberá haber una decisión judicial inmediatamente posterior al momento de la alegación del vicio que compromete la fiabilidad de la prueba o incluso en la etapa de admisibilidad de la acusación (compatible con la etapa intermedia, prevista en varios de los Códigos reformados de América Latina, o en la etapa de pre-trial, del sistema estadounidense) - lo que ocurra primero ${ }^{37}$.

epistemológicas y jurídicas sobre la admisión de la prueba (i.e., el principio de admisión de toda prueba relevante y las excepciones establecidas por reglas de exclusión jurídicas); 2) la práctica de la prueba de forma contradictoria, esto es, permitiendo la intervención de las partes en la misma; 3) la posibilidad de proponer pruebas contrarias a las ofrecidas por la otra parte procesal, de modo que permita vencer a éstas y/o corroborar una hipótesis fáctica distinta e incompatible; 4) la posibilidad de proponer pruebas de segundo orden (o pruebas sobre la prueba) que impugnen la fiabilidad de pruebas ofrecidas por la otra parte".

37 Y esto, a nuestro juicio, no constituiría una hipótesis de paternalismo epistémico indeseable (Vázquez, 2015, p. 140-142). En primer lugar, no se trata de un intento de proteger a los jueces (o jurados) de sí mismos (Vázquez, 2015, p. 141), sobre todo porque, no son los jueces quienes sufren las consecuencias adversas de un posible error judicial, proporcionado 
Sin embargo, existen muchas ventajas en tomar una decisión, en la etapa de admisibilidad probatoria, sobre el ingreso o salida de un elemento probatorio a un expediente. La más relevante de ellas se refiere a todo lo que esto representará en cuanto al ejercicio más denso del derecho de defensa: en este caso, la defensa podrá debatir el asunto de manera aislada, en un debate dedicado exclusivamente a este tema, sin preocuparse de enfrentar el al mismo tiempo, todos los demás quaestio facti y quaestio juris involucradas en el caso. Además, la eventual decisión por la remoción del elemento de prueba podrá dar paso incluso a la no iniciación o aún a la inviabilidad de continuar el proceso, siempre que no hubiera otros elementos de prueba que puedan sustentar la justa causa necesaria para el ejercicio del derecho de acción, o incluso cuando se reconoce que los demás elementos de prueba obtenidos fueron derivaron (por causalidad naturalística o normativa - Prado, 2019, p. 130) de aquella prueba considerada ilícita, en virtud de su falta de fiabilidad.

Hay más: la anticipación de la discusión sobre la admisibilidad de una determinada prueba podrá ser ventajosa incluso si se consideran los intereses de la acusación. Es que la depuración del elemento probatorio cuya fiabilidad esté comprometida favorece la posibilidad de abrir otras líneas de investigación y recolección de otros elementos de prueba (obtenidos de fuentes independientes) que no estén afectados/contaminados por los vicios de la prueba comprometida, posibilitando la continuación de la persecución penal, con menor pérdida de tiempo y mayor probabilidad de la punibilidad no se vea aniquilada por la prescripción.

A todo esto, claro, necesita adicionarse la observación de que mantener en el proceso elementos probatorios con escasa o nula fiabilidad aumenta los riesgos de errores judiciales, incluido el riesgo de condenaciones erróneas. Y, sin embargo, la lucha por la reducción de estos errores judiciales

\footnotetext{
por una equivocada valoración de una prueba no fiable, sino aquellos ciudadanos que sean destinatarios de la protección conferida por derechos fundamentales como la presunción de inocencia, contradictorio, de defensa amplia, etc. Y, considerando la posición de estos ciudadanos y la posición preferente de los derechos fundamentales, no vemos como inapropiada una mayor cautela epistémica en la evaluación de qué pruebas podrán integrar el acervo de informaciones a ser considerado en el razonamiento judicial. Por todas estas razones, resolver la cuestión en la etapa de admisibilidad estaría plenamente justificado.
} 
Sobre "La cadena de custodia de la prueba en el proceso penal", de Geraldo Prado

debe ser también una lucha de los órganos encargados de la persecución ${ }^{38}$ (a quien no debe interesar la condenación de cualquier persona, sino solo de aquella culpables del delito investigado), tanto por la necesidad de preservación de la legitimidad del sistema de justicia, así como por el propio objetivo de realización de la función motivadora de la norma penal (Ferrer Beltrán, 2007, p. 29-30), para quien considera esto como uno de los fines atribuidos al derecho penal.

Por otro lado, mantener el elemento de prueba cuestionado en el proceso y abordar el problema de la fiabilidad solo en el momento de la valoración trae serias desventajas, aun cuando se haga la reserva de que, en estos casos, el juez debería actuar "con un doble cuidado y mucho mayor esfuerzo justificativo" (Badaró, 2017, p. 534-536). En primer lugar, no es difícil intuir que, mientras esta prueba permanezca en el expediente, termine sirviendo como elemento de justificación de todas las decisiones adoptadas en las diversas etapas del procedimiento - admisibilidad de la acusación, decreto de medidas cautelares reales o personales (Armenta Deu, 2014, pág.129), autorización de medidas investigativas intrusivas, etc. - sin que la parte perjudicada por dicha decisión pueda obtener un debido pronunciamiento judicial sobre su impugnación, basado en la falta de fiabilidad de la prueba.

Además, dejar la cuestión para ser examinada en el momento de la sentencia, en el plano de la valoración probatoria, dificulta bastante las posibilidades de impugnación de esta decisión. Es decir: si la parte considera que el juez atribuyó algún valor probatorio a un elemento probatorio que no merecía ninguna credibilidad o incluso que el valor fue mayor de lo que era justificable para la especie, su inconformidad tendrá que ser formulada, junto con otros tantos temas (que pueden ir desde discusiones sobre la inobservancia de las normas de competencia hasta el uso indebido de los criterios para la aplicación de la sanción penal), en un recurso de

${ }^{38}$ Un buen ejemplo de esto puede observarse con el fenómeno del surgimiento de programas internos de integridad en las oficinas del Ministerio Público norteamericano. Se denominan Conviction Integrity Units (CIU), que actúan como comités para la prevención, identificación y corrección de errores judiciales, para lo cual examinan y evalúan casos de posibles condenas erróneas y mal desempeño por parte de los fiscales (Melo, 2014; Moreira, 2014). 
apelación, con límites cognitivos que no contribuyen a un examen más pormenorizado del tema.

Además de todo esto, aún habría que considerar, adoptando la noción de proceso como dispositivo - compuesto, como señala Prado (2019, p. 37), de elementos 'discursivos' y 'no discursivos' -, que la opción de dejar todo para ser resuelto por el juez en la sentencia, además de evidenciar los síntomas de la creencia de que los jueces son sujetos dotados de "superpoderes epistémicos" (Prado, 2019, p. 27) y de la ya mencionada sobreestimación del libre convencimiento (Prado, 2019 , p. 37), también es indeseable porque aumenta potencialmente el riesgo moral (Morais da Rosa \& Vieira, 2020) de una decisión que pueda contradecir las expectativas sociales. En la misma línea - y aún en el campo de los elementos 'no discursivos' -, será también mayor el riesgo de que, una vez dictada la sentencia (en la que haya sido utilizada determinada prueba no fiable), tal evento sea visto como un 'hecho consumado', dificultando su reforma o anulación ${ }^{39}$.

No obstante, como ya se señaló, el libro de Prado fue escrito en un momento en que el ordenamiento jurídico brasilero aún no disponía "de una regla específica sobre la cadena de custodia de las pruebas y la consecuencia de su violación" (2019, p. 128), la conclusión del autor se dirige a que la contaminación generada por la ruptura de la cadena de custodia ya tendría su referencia legal en el art. 157 del CPP, que reproduce el mandato constitucional (art. 5, LVI, de la Constitución Federal brasilera) que aboga por la inadmisibilidad, en el proceso, de la prueba obtenida por medios ilícitos.

Ésta, dicho sea de paso, fue la posición sustentada por el autor en el dictamen que dio origen al libro de 2014 y que se mantuvo en la obra de 2019. Y en apoyo a su posición, es importante decir que la Sección Sexta del Superior Tribunal de Justicia brasilero, en 2014, en el juzgamiento del Habeas Corpus no 160662/RJ, refiriéndose expresamente al dictamen de Prado en la Sentencia, aceptó la tesis de ilicitud ${ }^{40}$ probatoria en un caso

39 Prado (2019, p. 37) llama la atención sobre el hecho de como "los bajos índices de revisión de las condenas basadas en la aplicación de nuevas técnicas - como por ejemplo el examen de ADN" denuncian "el predominio d los elementos no discursivos en el ámbito procesal penal.

${ }^{40}$ La única reserva sobre el tema fue hecha en el voto del Ministro Rogério Schietti, quien, si bien acompañó a la Ponente, registró su disenso en relación al hecho de considerar que la hipótesis sería de ilegitimidad de la prueba y no de ilicitud, dado que, a su juicio y 
Sobre "La cadena de custodia de la prueba en el proceso penal", de Geraldo Prado

en el que se consideró quebrada la cadena de custodia o resguardo de la prueba proveniente de intercepciones telefónicas y telemáticas, habiendo la Ministra relatora hecho constar, expresamente en su voto, que "la prueba obtenida mediante intercepción telemática debe ser considerada ilícita, debido a la pérdida de su unidad, o, en palabras del dictamen de Geraldo Prado, la 'pérdida de la cadena de custodia de la prueba', que caracteriza el cercenamiento del derecho de defensa" ${ }^{41}$.

La decisión fue aún más lejos y, acogiendo la argumentación de que la ilicitud de aquellos elementos de prueba cuya integridad estaba comprometida se extendía, por nexo de antijuridicidad, a otras pruebas que integraban el acervo probatorio del caso, la Corte ordenó el envío del expediente a la primera instancia, para que el tribunal de primer grado examinara a qué otros elementos de prueba debería declararse la ilicitud derivada.

Como ya destacó en otro momento (Vieira, 2020, p. 31), aunque la reciente reforma legislativa impulsada por la Ley 13.964/2019 haya introducido en el Código procesal penal brasilero una serie de disposiciones regulando el régimen de preservación de la cadena de custodia de las pruebas, el legislador guardó silencio sobre las consecuencias procesales aplicables cuando existiesen situaciones en que quedara caracterizada la ruptura de la cadena de custodia de la prueba. No obstante tal silencio es, de hecho, lamentable, pues hubiera sido mucho más apropiado que el legislador hubiera abordado explícitamente el tema, lo cierto es que esto no modifica, en este sentido, el contexto en el que Prado desarrolló sus ideas, sosteniendo que el tratamiento reservado a los casos de ruptura de la

fundado en la doctrina clásica de Pietro Nuvolone, la afrenta se habría dado a una norma de derecho procesal o procedimental. Sin embargo, aunque la distinción entre pruebas ilícitas y pruebas ilegítimas continúe arraigada en la doctrina procesal penal brasilera y todavía forme parte de la tradición de la jurisprudencia de los tribunales, lo cierto es que, con la redacción dada por la Ley 11.690/08, al art. 157 del Código Procesal Penal ("Son inadmisibles, debiendo ser eliminadas, las pruebas ilícitas, así entendidas las obtenidas en violación de normas constitucionales o legales"), no debería haber más espacio para tal distinción, en la medida en que el legislador, al conceptualizar las pruebas ilícitas, hizo referencia a las situaciones de obtención con violación a normas constitucionales y legales, sin excepción de ninguna naturaleza.

${ }^{41}$ Brasil, STJ, HC 160.662, Rel. Ministra Assusete Magalhães, Sección Sexta, DJE de 17/03/2014, p. 2. 
cadena de custodia habría de ser el mismo destinado a las pruebas ilícitas, con su consiguiente inadmisibilidad.

En cierta medida, puede decirse incluso que la posición adoptada por Prado, aun cuando el Código no contenía disposiciones específicas sobre la preservación de la cadena de custodia de las pruebas, adquiere cierto refuerzo cuando el legislador reconoce la importancia del tema y comienza a abordar de manera expresa, dedicando varias disposiciones legales al tema.

Por otro lado, el cambio legislativo no siempre tiene la capacidad de promover la transformación cultural necesaria para que los sujetos intervinientes en la persecución penal comprendan la importancia de una actividad probatoria epistémicamente orientada, dotando el juicio sobre los hechos de la relevancia necesaria y actuando para que los elementos de la prueba considerados en el juicio estén dotados de licitud, integridad y fiabilidad. Para ello, será necesario un arduo trabajo de concientización de los actores y operadores del sistema de justicia, en la dirección de un cambio de comportamiento ${ }^{42}$ que favorezca la realización de juicios más justos y equitativos, basados en evidencias más confiables, con la consecuente reducción de los riesgos de decisiones erróneas e injustas.

\section{Para concluir: algunas palabras sobre un incansable intelectual}

La cadena de custodia de la prueba en el proceso penal es un libro-símbolo. Representa una sensible madurez intelectual de una vida dedicada a la consolidación de la democracia brasilera, de un autor que siempre estuvo atento a la historia de su país. Es una obra que significa la labor fina y creativa de Geraldo Prado, quien logró proponer un giro paradigmático en la

\footnotetext{
${ }^{42}$ Buenos ejemplos del inicio de este cambio comportamental son la Resolución SEPM N ${ }^{\circ}$ 755, dl 17 de septiembre de 2020, de la Policía Militar de Río de Janeiro (Río de Janeiro, 2020), que regula las instrucciones generales de los procedimientos arquetipos de la cadena de custodia de vestigios, dirigidos a determinar la actuación de los policías que asisten a eventos policiales en el Estado, y también la publicación, por parte del Ministerio de Justicia de Brasil, de un manual modelo de procedimiento operacional para pericias criminales, en las más diversas áreas de la pericia forense (Brasil, 2013).
} 
Sobre "La cadena de custodia de la prueba en el proceso penal", de Geraldo Prado

doctrina y jurisprudencia brasileras, invitándolas a pensar en el límite que condensa las tensiones cotidianas del proceso penal: la prueba penal. El texto representa la reflexión de un autor que conoce los tormentos prácticos del proceso penal, pero que no se dejó absorber por los sinsentidos del sistema de justicia penal. Se revolucionó con selectas reflexiones filosóficas, siguiendo un camino que lo llevó a comprender el proceso penal también a través de la Historia de las Ideas y Cultura Jurídicas.

Geraldo Prado, incansable defensor de un proceso penal democrático, pasó por las carreras del Ministerio Público, Magistratura, jubilándose como vocal del Tribunal de Justicia de Río de Janeiro. Formalizó su saber jurídico con los títulos de maestría (Universidad Gama Filho / RJ), doctorado (Universidad Gama Filho / RJ) y posdoctorado (Universidad de Coimbra).

Fue profesor de procesal penal de la Universidad Federal de Río de Janeiro (UFRJ), donde fundó el grupo de investigación As Matrizes Autoritárias do Processo Penal Brasileiro. Recientemente (septiembre/2020), se retiró del cargo de profesor de la UFRJ. Solo del cargo, porque continúa difundiendo, con sus conferencias y dictámenes jurídicos, enseñanzas por todo Brasil y el mundo. Artífice de la palabra y del pensamiento que ilumina, se ha dedicado a consultorías jurídicas.

Es autor de artículos jurídicos fundamentales y obras relevantes para el establecimiento de una cultura constitucional en el proceso penal brasilero, con énfasis en los libros Sistema Acusatório: a conformidade das leis processuais penais brasileiras e Elementos para uma análise crítica da Transação Penal.

Dada la extensión de su intensa trayectoria académica, del vigor emprendido por años en el oficio judicial, se equivoca quien se atreva a pensar que de todo este cansancio saldría victorioso. Geraldo Prado se renueva constantemente, repensando el derecho procesal penal, cuestionándose sobre nuevas posibilidades para reducir la extrema desigualdad socio racial que atraviesa el proceso penal brasilero.

Vendrán otros artículos y libros, porque es en la escritura donde él excava los áridos suelos de la dogmática procesal penal, que, en cierto modo, todavía cuelga somnolienta en el sentido común. Es en la escritura que él hará que el Derecho Procesal Penal escuche algo real sobre la dignidad humana. Parafraseando a Ferreira Gullar, una parte de Prado "es permanente; otra parte se conoce de repente". 


\section{Bibliografía}

Accatino, D. (2016). La arquitectura de la motivación de las premisas fácticas de las sentencias judiciales y su función como garantía. Disponible e http://iusfilosofiamundolatino.ua.es/download/articulo\%20ilatina\%20 Alicante\%20Daniela\%20Accatino.pdf. Último acceso 27/10/2020.

Agamben, G. (2009). O que é o contemporâneo? e outros ensaios. (V. Nicastro Honesco Trad.). Chapecó, SC: Argos. . (2019). Signatura Rerum: sobre o método (1ª ed.). (P. P. Andrea Santurbano, Trad.). São Paulo: Boitempo.

Aguilera, E. (2020). Una propuesta de aplicación de la epistemología jurídica en la investigación del delito. En J. Ferrer Beltrán y C. Vázquez (eds.), Del derecho al razonamiento probatorio (pp. 17-43). Madrid: Marcial Pons.

Andrés Ibáñez, P. (2007) Los hechos en la sentencia penal. Ciudad de México: Fontamara.

Armenta Deu, T. (2014). A prova ilícita. Um estudo comparado. Madrid: Marcial Pons.

Ávila, H. (2005). Teoria dos princípios jurídicos. Da definição à aplicação dos princípios jurídicos. (12a ed.). São Paulo: Malheiros.

Badaró, G. H. (2017). A cadeia de custódia e sua relevância para a prova penal. Em R. Sidi y A. Bezerra Lopes (eds.), Temas atuais da investigação preliminar no processo penal (pp. 517-538). Belo Horizonte: D’Plácido. . (2019). Epistemologia judiciária e prova penal. San Pablo: Thomson Reuters/Revista dos Tribunais.

Baytelman, A. y Duce, M. (2004). Litigación penal y juicio oral. Ecuador: Fondo Justicia y Sociedad (Fundación Esquel - USAID).

Binder, A. (2004). La fuerza de la Inquisición y la debilidad de la República. Política Criminal Bonaerense, 1(1), 230-258.

Cecconello, W. W., de Ávila, G. N., y Stein, L. M. (2018). A (ir)repetibilidade da prova penal dependente da memória: uma discussão com base na psicologia do testemunho. Revista Brasileira de Políticas Públicas, 8(2), 1057-1073.

Cecconello, W. W., y Stein, L. M. (2020). Prevenindo injustiças: como a psicologia do testemunho pode ajudar a compreender e prevenir o falso 
Sobre "La cadena de custodia de la prueba en el proceso penal", de Geraldo Prado

reconhecimento de suspeitos. Avances en Psicología Latinoamericana, 38(1), 172-188.

Cunha Martins, R. (2012). O mapeamento processual da verdade. En G. Prado, R. Cunha Martins y L.G.G. Castanho de Carvalho (eds.), Decisão judicial: A cultura jurídica brasileira na transição para a democracia (pp. 71-86). San Pablo: Marcial Pons.

De Sousa Santos, B. y Paula, M. M. (2013). Epistemologias do sul. San Pablo: Cortez.

Dei Vecchi, D. (2019). La no tan sana crítica racional. En letra: Derecho Penal, 5(9), 40-55.

Duce, M. J. (2020). La etapa de preparación del juicio oral y su rol en el control de admisibilidad probatoria en Chile. Quaestio facti. Revista internacional sobre razonamiento probatorio, (1), 103-131.

Dussel, E. (2011). Filosofía de la liberación. Ciudad de México: Fondo de cultura económica.

Ferrajoli, L. (1995). Derecho y razón: teoría del garantismo penal. Madrid: Trotta. . (2004). Epistemología jurídica y garantismo. Ciudad de México: Fontamara.

Ferrer Beltrán, J. (2007). La valoración racional de la prueba. Madrid: Marcial Pons.

Foucault, M. (2018). Microfísica do Poder. (7aed). Rio de Janeiro: Paz e Terra. Gallardo, E. (2020). El juez de garantía y el debido proceso en el estado democrático de derecho. Boletim Revista do Instituto Baiano de Direito Processual Penal (Trincheira Democrática), 3(9).

Gascón Abellán, M. (2010). Los hechos en el derecho. Madrid: Marcial Pons. . (2013). Prueba científica. Un mapa de retos. En C. Vázquez (ed.), Estándares de prueba y prueba científica: ensayos de epistemología jurídica (pp. 181-201). Madrid: Marcial Pons.

Gascón Inchausti, F. (1999). El control de la fiabilidad probatoria: "prueba sobre la prueba» en el proceso penal. Valencia: Ediciones Revista General de Derecho.

González Lagier, D. (2019). Quaestio facti: ensayos sobre prueba, causalidad y acción. Lima: Palestra.

González, M. R (2013). La cadena de custodia en el proceso penal español. Diario La Ley, (8187). 
Antonio Vieira, Saulo Murilo de Oliveira Mattos

Grinover, A. P. (2013). O processo: III série: estudos e pareceres de processo penal. Brasília: Gazeta Jurídica.

Gomes Filho, A, M. (2013) A motivação das decisões penais. (2a ed.). San Pablo: Revista dos Tribunais.

Guarneri, J. (1952). Las partes en el proceso penal. (C. Bernaldo de Quirós, Trad.). Puebla: Editorial Científica Poblana.

Haack, S. (2015). Perspectivas Pragmatistas da Filosofia do Direito. (A. de Godoy Vieira y N. Schneider, Trads.). San Leopoldo: Unisinos.

Instituto Brasileiro de Ciências Criminais (2017). Reforma do Código de Processo Penal Brasileiro. Contribuições do Instituto Brasileiro de Ciências Criminais (IBCCRIM) ao Projeto de Lei 8.045/2010. Maio de 2017. Disponible en: <https://www.ibccrim.org.br/docs/2017/20170601_ ReformaCPPIBCCRIM.pdf>. Último acceso julio 2020.

Lopes Jr, A. y Morais da Rosa, A. (2015). A importância da cadeia de custódia para preservar a prova penal. Disponible en: https://www. conjur.com.br/2015-jan-16/limite-penal-importancia-cadeia-custodiaprova-penal. Último acceso 06/02/2020.

Matida, J. (em prensa). Epistemologia Jurídica aplicada ao processo penal: reflexões sobre os poderes probatórios do julgador na realidade brasileira. En J. Correa de lima y R.R.R. Casara. (coords.), Temas para uma perspectiva crítica do direito: homenagem ao professor Geraldo Prado. Matida, J. y Herdy, R. (2019). As inferências probatórias: compromissos epistêmicos, normativos e interpretativos. Revista do Ministério Público do Estado do Rio de Janeiro, 73, 133-155.

Marrero, D. (2015). Lineamientos generales para una epistemología jurídica. En A. Páez (coord.), Hechos, evidencias y estándares de prueba. Ensayos de epistemología jurídica (pp. 15-36). Bogotá: Uniandes:

Melo, J. O. (2014). Promotoria esconde provas e condenação é revertida. Disponible en: <https://www.conjur.com.br/2014-jul-08/eua-criamsistema-controle-mp-evitar-condenacoes-erradas $>$. Último acceso 13/06/2019.

Miranda Estrampes, M. (2004). El concepto de prueba ilícita y su tratamiento en el proceso penal. ( $2^{\mathrm{a}} \mathrm{ed}$.). Barcelona: J. M. Bosch.

Morais da Rosa, A. y Vieira, T. (2020). Como o risco moral é variável da decisão judicial de prisão cautelar. Disponible en: < https:// 
Sobre "La cadena de custodia de la prueba en el proceso penal", de Geraldo Prado

canalcienciascriminais.com.br/como-o-risco-moral-e-variavel-dadecisao-judicial-de-prisao-cautelar/>. Último acceso 01/11/2020.

Moreira, R. de A. (2014). A ética do promotor de justiça criminal nos Estados Unidos da América. Jus Navigandi, 19(4082). Disponible en: $<$ https://jus.com.br/artigos/31547>. Último acceso 15 jun. 2019.

Nicolitt, A. L. (2014). A duração razoável do processo. (2da ed.). San Pablo: Revista dos Tribunais.

Nieva Fenoll, J. (2013). La duda en el proceso penal. Madrid: Marcial Pons. Páez, A. (2015). Introducción. La epistemología y el derecho. En A. Páez (coord.), Hechos, evidencias y estándares de prueba. Ensayos de epistemología jurídica (pp. 1-12). Bogotá: Uniandes.

Prado, G. (2006). Sistema acusatório: a conformidade constitucional das leis processuais penais. Lumen Juris.

. (2013). O Processo Penal Brasileiro vinte e cinco anos depois da Constituição: transformações e permanências. Revista da Emerj, 18(67), 550-569.

(2014). Prova penal e sistema de controles epistêmicos. A quebra da cadeia de custódia das provas obtidas por métodos ocultos. São Paulo: Marcial Pons.

. (2015a). Parecer: Fiabilidade probatória e valoração da prova. Rio de Janeiro.

. (2015b). A quebra da cadeia de custódia das provas no processo penal brasileiro. En M.M.G. Valente, G. Prado, N.J. Giacomolli, y E.D. Silveira, Prova penal: estado democrático de direito (17-37). Florianópolis: Empório do Direito.

. (2019). A cadeia de custódia da prova no processo penal. São Paulo. Marcial Pons.

. (2019b). La cadena de custodia de la prueba en el proceso penal. Madrid. Marcial Pons.

. (2019). Parecer: Conselho Seccional da Ordem dos Advogados do Brasil como Assistente do Ministério Público no Marco do Processo Penal brasileiro. Revista brasileira de ciências criminais, 161, 333-364 [@geraldoprado]. (24/07/2020). La versión en portugués del libro A cadeia de custódia das provas no processo penal está agotada. Estoy trabajando artesanalmente en la próxima edición, que incorporará el 
Antonio Vieira, Saulo Murilo de Oliveira Mattos

tratamiento legal conferido al tema por la Ley $n^{\circ} 13.964 / 2019$, conocida como Paquete Anticrimen[...]". Recuperado de https://www.instagram. com/p/CDB_Oieg3ip [N. de T.: la publicación de Instagram original se encuentra en idioma portugués].

Prado, G., Carvalho, L. G. G. C., y Martins, R. C. (2012). Decisão Judicial. A cultura jurídica brasileira na transição para a democracia. São Paulo: Marcial Pons.

Rio de Janeiro (2020). Secretaria de Estado da Polícia Militar. Resolução SEPM n 755 de 17 de setembro de 2020. Dispõe sobre as instruções gerais de procedimentos padrão da cadeia de custódia de vestígios, acionamento do CCRIM e solicitações de perícias (IG-001/2020) na Polícia Militar do Estado do Rio de Janeiro.

Roxin, C. (2000). Derecho procesal penal. Buenos Aires: Editores del Puerto. Sánchez-Vera Gómez-Trelles, J. (2012). Variaciones sobre la presunción de inocencia. Análisis funcional desde el Derecho penal. Madrid: Marcial Pons. Secretaria Nacional de Segurança Pública (2013). Procedimento operacional padrão: perícia criminal. Brasília: Ministério da Justiça.

Taruffo, M. (2013). La aplicación de estándares científicos a las ciencias sociales y forenses. En C. Vázquez (ed.), Estándares de prueba y prueba científica (pp. 203-214). Madrid, Marcial Pons. . (2016). Uma simples verdade. O juiz e a construção dos fatos. (V. de Paula Ramos, Trad.). San Pablo: Marcial Pons.

Tavares, J. (2019). Teoria do Injusto Penal. (4ta ed.). San Pablo: Tirant Lo Blanch.

Ubertis, G. (2020). Quaestio facti e Quaestio iuris. Quaestio facti. Revista internacional sobre razonamiento probatorio, 1, 67-74.

Urazán Bautista, J. C. (2005). La cadena de custodia en el Nuevo Código de Procedimiento Penal. Disponible en: http://fundacionluxmundi.com/ custodia.php. Último acceso: 15/10/2020.

Vázquez, C. (2015). De la prueba científica a la prueba pericial. Madrid: Marcial Pons.

Vieira, A. (2020). A cadeia de custódia da prova no processo penal: algumas notas sobre as alterações promovidas pela lei 13.964/2019 (pacote anticrime). Boletim Revista do Instituto Baiano de Direito Processual Penal, 3(7), 27-32. 
Sobre "La cadena de custodia de la prueba en el proceso penal", de Geraldo Prado

Zoukis, C. (2014). Prosecutorial Misconduct: Taking the Justice Out of Criminal Justice. Disponible en: < https://www.prisonlegalnews.org/ news/2014/nov/8/prosecutorial-misconduct-taking-justice-outcriminal-justice/>. Consultado el: 16/06/2019. 